\title{
Songs for Sailors and Lovers
}

\author{
Joel Lidov
}

We know about as much, or as little, about Sappho's own life as we do about other archaic and early classical poets, indeed maybe more if we believe the later ancient gossip about her, but we do not have so clear an idea about the nature of her work: what types of songs the fragments represent, whom she wrote for, on what occasions. Even if these questions cannot be fully answered, at least the newly published fragments that add to our knowledge of Book One of Sappho also add to our ability to understand the internal structures of many of her poems and give us a chance to study the similarities and differences among a large group of them. ${ }^{1}$ We are in a better position than before to interpret them, both in their own terms- $\Sigma \alpha \pi \varphi \dot{\omega} \varepsilon \dot{\varepsilon} \kappa \alpha \pi \varphi \circ \hat{\varsigma} \varsigma \alpha \alpha \varphi \eta v i \zeta \varepsilon \varepsilon \nu$-and through comparisons with other ancient poetry, and so to form hypotheses about the nature of her poetic work before we try to give an account of small fragments, out-of-context quotations, and questionable evidence from their ancient reception. ${ }^{2}$ Here I will focus on the structure of individual poems in

1 I am deeply indebted to Dirk Obbink for providing the opportunity to study these new fragments and for his correspondence, comments and assistance throughout. André Lardinois has been, as always, a wise advisor at all stages of the development of this paper and its predecessors, and I am grateful too to Toni Bierl for his comments on the first draft. The second section of this article originated in a paper for the conference "Song Regained" (UCL, London 2014, organized by M. Alexandrou, C. Cary, and G. D'Allesio) and the others are expanded from the panel "New Fragments of Sappho" (scs, New Orleans, 2015, organized by A. Lardinois); I owe thanks to the organizers and to members of the audiences, and particularly to follow-up discussions and correspondence with E. Cingano, J. Danielewicz, and E. Stehle. Where I discuss matters that are properly paleographical or papyrological, I have relied on the published editions and the text in this volume, and on the guidance of their editors, but I may not have always sought (or understood) the latter when I should, and bear sole responsibility for any mistakes, as well as for other errors.

2 Even before these discoveries, arguments from both internal and comparative evidence had put in doubt some of the old notions of monodic and of personal lyric in favor of recognizing choral and public features in Sappho's work generally. See Lardinois (1996) and Calame (2012a) for different approaches to the same conclusion; there is a useful general discussion, with bibliography in Cingano (2003) 17-25. I do not put these aside, especially given the apparent confirmation of them in the recent additions to Sappho fr. $5^{8}$ and now

(C) JOEL LIDOV, 2016 | DOI: 10.1163/9789004314832_005

This is an open access chapter distributed under the terms of the Creative Commons Attribution- 
order to draw some broad conclusions, and to justify some speculations, about the type or types of poetry in Book One. ${ }^{3}$ I will begin by drawing attention to a grammatical point in what has been called the 'Brothers' poem: the subject of $\pi \dot{\varepsilon} \mu \pi \eta \nu$ in line 5(9). It has been widely misconstrued ever since the poem's first prepublication, and I think that the misconstruction involves our conception of the speaker and is symptomatic of our difficulties in making sense of the whole group. To be consistent with my intentions of working from internal evidence, I will call this song the Charaxos poem, since 'brother' never occurs in it. I will then examine, first, the songs-including the Charaxos poemwhich, I propose, constitute a group of prayers for safe return, and, second, a group of songs about love. My concern in the first group will be with what they have in common, and in the second with how Sappho creates individual voices on a common theme. At the end I will return to the Charaxos poem, to suggest-'demonstrate' would go beyond the limits of our knowledgethat the appreciation of the individual voices within a common group points both to a performance context and to a way of thinking about Sappho in the poems.

in the new addition of a first person plural in Sappho fr. 17.11, though I try not to rely on too many assumptions about archaic society. For background on the tradition of interpretation, see Parker (1993), Lefkowitz (1996), and the highly critical overview of modern theories in Schlesier (2014a) 74-95.

3 I confine my remarks to Book One because I see no reason to assume, a priori, that its contents form a unity with the poems in other books. I regard it as possible that the metrical arrangement is not just an arbitrary device of the Hellenistic editors. In Sappho's work some meters may have been particularly suited for some topics or occasions, and these groupings may have formed the basis of the compilation. Most notable is the minimal presence of Aphrodite / Kypris as an addressee or character and of the singing persona's experience of passion outside of Book One (Aphrodite is often mentioned elsewhere to enhance a focus on e.g. marriage or Adonis; see the discussion by Schlesier, this volume), and, especially, the absence of the Muses, who are frequent in the scraps of Books Three and Four (see Lidov [2009]). Similarly, I do not assume an essential Sappho whose concerns and psychology can automatically be transferred from one book, or poem, to another. (Bierl [2003], though devoted to only one poem, shows in detail the ways in which various essentialist presuppositions about the character of the poet or of lyric have dominated interpretation.) For formal features of structure, dialect or vocabulary (when function is taken into account), of course, we can look at the whole corpus, and there is no denying a distinctive excellence of poetic style, often achieved through similar means. 


\section{You or Me?}

In the first line of the second full stanza, the pronoun है $\mu \varepsilon$ has almost universally been taken to be the object of the verb, leading to the supposition that the persona of the singer is instructing the chatterer, $\sigma \dot{\varepsilon}$, the addressee, to send her to conduct a prayer. So, the sentence

$$
\begin{aligned}
& \tau \alpha \hat{\tau} \alpha \text { vónc } \theta \alpha \text {, }
\end{aligned}
$$

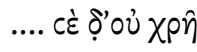

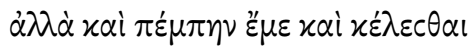

10

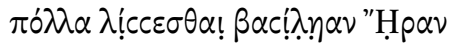

is understood as 'It is necessary that you not think these things but (it is necessary that you) send and order me .... The persona of the first person is generally taken to be identical or similar to the persona who does in fact pray in the other poems. The spelling $\tilde{\varepsilon} \mu \varepsilon$ is an emphatic pronoun, just like $\sigma \dot{\varepsilon}$, which we know must be the emphatic (or accented or orthotone) form because it begins the sentence and therefore cannot be the enclitic.

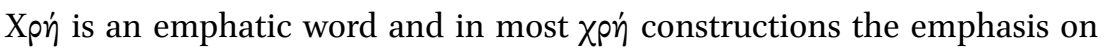
the obligation includes an emphasis on the action in a dependent infinitive (often inferred from the previous clause). An accompanying pronoun typically

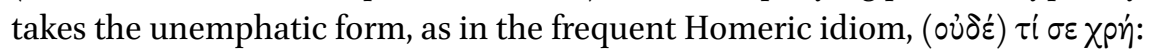

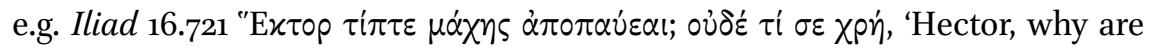
you holding off from the fight? You must not', or (with a slight variant) Odyssey

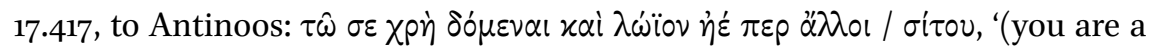
superior man,) therefore you must give bread even better than the others'. In both these examples the speaker emphasizes that it is particularly appropriate for the addressee to do the action, but the addressee is presupposed by the context or the previous second-person form, and the emphasis is on the obligation to act. ${ }^{4}$ This is even clearer when 'you' is indefinite and not even presupposed,

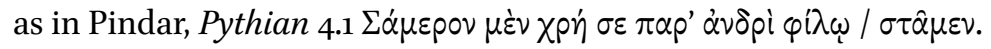

The order of $\chi \rho \eta \dot{n}$, the infinitive, and its noun or pronoun subject can be varied. So we find, with an accented but essentially indefinite word, the subject

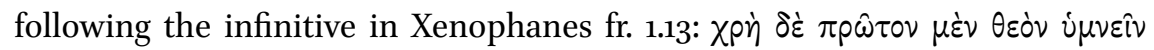

4 Strictly, of course, we can't know that the pronoun $\sigma \varepsilon$ in these two examples was not accented, but the run of the word order in the phrase, which always places it after another word, is against the accent. Even more so is the parallel phrase $\tau i$ ("̈ $\tau \tau \varepsilon \delta ́) ~ \mu \varepsilon \chi \rho \hat{\eta}$, which is found four times (Il. 9.67; Od. 19.118, 21.110, 23.337). 
$\varepsilon \ddot{\varphi} \varphi p o v \alpha \varsigma \alpha{ }^{\prime} v \delta \rho \alpha \varsigma$ 'It is necessary first that gracious men sing the god, ...' (apart from the guidance offered by the meaning, participles in line 15 make clear which accusative is the subject). An enclitic pronoun may also follow the infinitive for which it provides the subject, as, for example, in Alcaeus fr. 332:

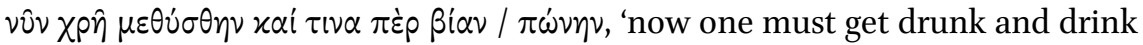
with strength', where $\tau i v \alpha$ follows one infinitive and precedes another. Such a positioning may be normal when there are two infinitives; it is also found with

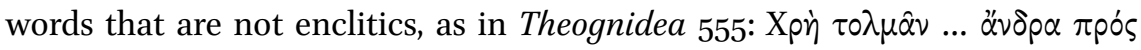

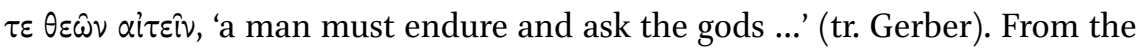
examples we have, we can see that the position of है $\mu \varepsilon$ in line 9 of the Charaxos song would be entirely normal for a subject of the infinitives, but we cannot conclude simply on the basis of the order of the infinitives and $\tilde{\mu}^{\prime \prime} \mu \varepsilon$ whether $\sigma \varepsilon$ or है $\mu \varepsilon$ is the likely subject. We do see in these examples that when the infinitive phrase is extended, the subject-pronoun does follow $\chi p \eta$; as far as I can find, this is a tendency but not a rule (see Iliad 9.10o). At the same time, we can see that its position in the sentence does not explain why an emphatic form would be used if the unemphatic would carry the same meaning. So we must look to the uses of the emphatic pronouns in $\chi p \eta$ constructions.

The optional oblique cases of emphatic pronouns are not used lightly or often with $\chi p \eta \dot{n}$. In such sentences the emphasis is on the agent rather than

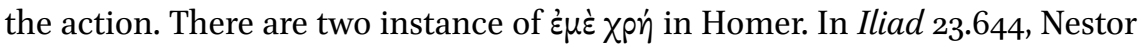
compares his current state, bound to old age, to his younger self; the emphasis is on the contrast. In Odyssey 23.250, Odysseus tells Penelope of the ponos

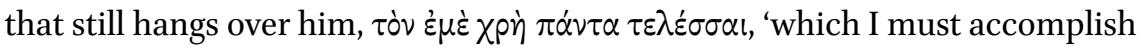
completely'; here, the infinitive phrase $\tau \dot{v} v . . . \tau \varepsilon \lambda \varepsilon \varepsilon^{\sigma} \sigma \alpha \iota$ is a placeholder for the action to be described and the emphasis is on the fact that it is he who is not yet

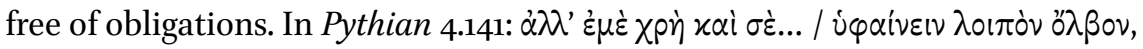
Jason, making a contrast of persons, is insisting to his antagonist Pelias that the two of them must act together: '(there are mortals who ignore consequences, but) you and I ... must weave our future good fortune'. In all other examples in Pindar when $\varepsilon^{\prime \prime} \mu \varepsilon$ is used with $\chi \rho \eta$, it is the first word (or first after the

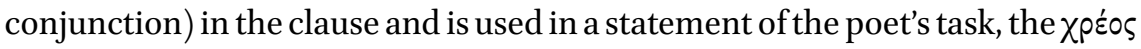
motif. ${ }^{5}$ In such passages the position and the emphatic form agree in making the poet the topic.

In Sappho's passage, $\sigma \varepsilon$ refers back to the subject of a previous verb, and could be presupposed, but the immediately previous sentence had the gods as subject, so $\sigma \varepsilon ́$ is a contrastive topic, reestablishing "you" as the agent under

5 There are no other uses of either form of $\sigma \varepsilon$ with $\chi \rho \eta$ in Pindar. 
discussion after the transitional gnome: 'The gods know what will happen; you must not think about such things'. The pronoun is then incorporated into a 'not A but B' construction. This construction does contrast 'think' and 'send', but if that were the main contrast intended ('you must not think but send'), it would be a typical $\chi \rho \eta$ construction with a primary emphasis on the action and there would be no call for the second pronoun to be emphatic. To explain है $\mu \varepsilon$ we must understand it in contrast to $\sigma \dot{\varepsilon}$. Because subjects and objects are not parallel, they cannot be in contrast in a 'do not do A but B' construction. There are no grounds (other than an interpretive presupposition) in our text or in comparable texts for taking this as a compression of two separate statements: 'but you must send someone, and I am the person you must send'. It is a consequence of the normal Greek semantics, or pragmatics, of pronouns in a

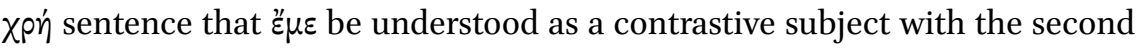
infinitive, $\pi \dot{\varepsilon} \mu \pi \eta v$ : 'you must not think these things, but $I$ must send .... ${ }^{6}$

Who is this persona cantans, who makes no specific reference to her own participation as a performer of song or prayer, but only to herself as the initiator

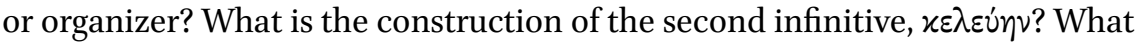
happens to the person signified by $\sigma \varepsilon$ ? These are questions of interpretation, and it will be helpful first to explore what kind of prayer this is, and how Sappho represents the persona singing in her poems, before I offer my answers to them.

\section{Prayers for Safety}

\section{Prayer Form}

We now know that Sappho 5, addressed to the Nereids, begins with $\pi$ ótvial (as proposed by Diels; see app. crit. in Voigt's edition), rather than with the widely

6 I take the first $x \alpha$ i not as correlative, but to emphasize the following phrase (see Denniston [1954] 316-317 S.v. $x \alpha$ í II.c) or to indicate that taking positive action is closely connected to the prohibition of vain speech (Denniston [1954] 3, s.v. $\alpha \lambda \dot{\alpha} \mathrm{I}$.(iii)(a), on the omission of $\mu$ óvov after a preceding negative; see Obbink [2014b] 43 ad loc.): 'but (it is) also (necessary) for me to send .... The use of $x \alpha$ í, however, is not relevant to the construction of है $\mu \varepsilon$. The fact that the activities are different does not alter the primary contrast in subjects; when Pindar uses है $\mu \varepsilon$

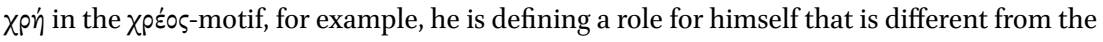
victor's. Finally, in insisting that the emphatic form cannot be ignored, I assume that Sappho does not make her word choice merely metri gratia but follows the norms of her language. In contemporary, spoken English 'myself' often drives out 'I' or 'me,' but there is no evidence of that in Early Greek - freely inserted statements of self-importance, not justified by the expressive structure, are not found. (I am grateful to Prof. Cingano for a discussion of this problem; see further his examination of $\chi$ p $\eta^{-}$-statements in Cingano [2003] 30-33.) 
accepted Kú $\pi$ pls, and that, in consequence, the address to Kypris at the end is not the closing of a ring but is a new topic. This confirms that the poem did not follow the standard model of prayer that has been much discussed in the last century. ${ }^{7}$ In that model a prayer has three parts. First, and most importantly, the god is invoked by name and this invocation is elaborated. The elaboration may include other names and cult-titles, associated deities, descriptive appellations, genealogy, locations and favorite haunts. The invocation may also include a foreshadowing of the contents of prayer, though that is not necessary. The god's name comes at the very top, at most preceded by an exhortation to the prayer or announcement of it - 'let us sing of', or 'I beseech you'. This invocation makes the god the most prominent figure, formally the object of attention (even if the choice of language dramatizes the petitioner's emotional state). In Fr. 5, however, the Nereids are addressed only with a simple title that recognizes their authority.

The second part goes by various names among scholars-sanctio or argument or omphalos or hypomnêsis. Here something is said which establishes a rapport between the supplicant and the god; it can aim to please the god with a recitation of his powers or it can be a reminder of other occasions of worship or request, or of the god's past or habitual activity (typically beginning with a relative pronoun, 'if ever', or a second-person pronoun). The material for this part might give an indication of why the god is the appropriate deity at the moment, in which case it may hint at what the petitioner is seeking. In the prayer to the Nereids, nothing is said about them.

The request is made explicit in the third part, which may be a prayer for a result, brought about by the god directly or —in a cletic prayer-by the god's arrival. This final prayer is, of course, directed to the god who was invoked in the beginning. In the Nereids poem, they were prayed to at the start, but they have been long forgotten by the end, and the final prayer is made to Kypris.

There are several examples of this form in Sappho and Alcaeus. Alcaeus offers a clear, well-elaborated example of an invocation in a cletic hymn to the Dioscuri (fr. 34); he includes genealogy, name, place of origin, and a sketch of their typical appearance, followed by a description of their powers in action. He has another sapphic stanza, fr. 308, that calls on Hermes by his location and a glorified genealogy. The one surviving line that opens his Hymn to Apollo (fr. 307), ' $\Omega \nu \alpha \chi$ "A $\pi \circ \lambda \lambda \circ \nu, \pi \alpha \hat{\imath} \mu \varepsilon \gamma \alpha \dot{\lambda} \omega \omega$ Sios, contains a name, title, and expanded patronymic. Sappho has a single line invoking the Graces (fr. 53), Bродо $\dot{\alpha} \chi \varepsilon \varepsilon \varsigma$

7 The original study is Norden (1956) 143-176, 391-393. See also Bremer (1981); Danielewicz (1974); Furley and Bremer (2001); Race (1982a). 


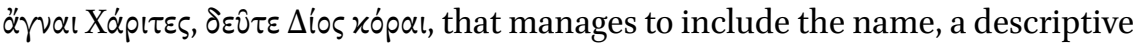
epithet ('with rosy hands'), a cult term ('holy'), the parentage ('maidens of Zeus'), and a brief summons ('hither'). Sappho's prayer to Aphrodite is one of the best known examples - it begins with a fulsome invitation to 'ornatethroned immortal Aphrodite, wile-weaving daughter of Zeus', and proceeds to a recollection of her past appearance before the final prayer. It also (as I will discuss below) illustrates how the form can be artfully complicated.

\section{Prayers for Safety}

The prayer to the Nereids is not the only one lacking the expected elaborate invocation. In Sappho, Book One, such poems are about the return of a traveller at sea. The obvious ones are the Nereid song (fr. 5 ), the Charaxos poem, and probably the prayer to Hera (fr. 17). There are also other fragments with vocabulary suggestive of the travel theme, although we cannot know their structures. In the case of the Nereid song and the prayer to Hera, the lack of conformity with the pattern has been observed, or brushed aside, by previous scholarship, which mostly focussed on the question of whether or not these and some other fragments were propemptica, a formal type of prayer for sea travel. These studies largely came to nothing, because it proved impossible to identify the propempticon as a specific genre before the Hellenistic era. They also mostly ignored the difference between good wishes for a traveller leaving and one returning. ${ }^{8}$ Certainly some of them, especially the prayer to the Nereids, contain propemptic motifs, such as can be seen in Theognidea 691-692, which joins the wish for happiness and success in the voyage out with one for a happy return:

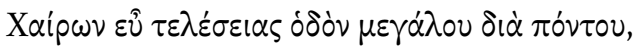

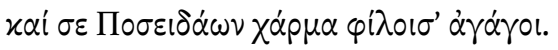

May you rejoice in the success of your journey over the great sea, and may Poseidon bring you as a joy to your friends.

8 On the vocabulary of fragments 15 and 20, suggesting a sea-faring theme that overlap with these, see Obbink (2014b) 35 with note 7; Ferrari (2014) 12; and, in addition, Theander (1943) 146-147, and Treu (1963) 184-185, who discuss the question of the propempticon. Francis

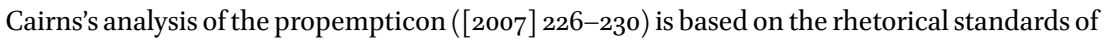
the Roman period; although he understands the instances in Sappho as analyzed by Page, he does make the distinction between the directions of travel (p. 116). Wachsmuth (1977) argues persuasively that early prayers for a voyage should be thought of as a collection of motifs rather than as a determined form. 


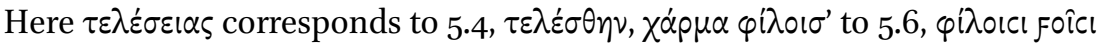
$\chi \alpha \dot{\rho} \alpha \nu$ and the mention of Poseidon reflects the awareness of dependence on the gods, corresponding to the prayer to the Nereids itself. ${ }^{9}$

I suggest that at the formal level the propemptic motifs in Sappho's poems make them a special case of a more general type of song, one which expresses the anxieties surrounding the desire for a safe return from danger. We can see a set of overlapping characteristics in a group that includes these three songs of Sappho and Alcaeus fr. 129, which expresses a prayer for return not from the sea but from exile, probably the internal exile on Lesbos that Alcaeus describes in frag. 13ob. In all of these, the poet invokes deities, but only minimally or after the song begins. What the structure of these prayers makes prominent is not a god, but the situation, that is, the danger that threatens the speaker, and the procedure by which he or she seeks release from it. A god is introduced, midway, to provide a solution, but the end of the poem is not a prayer for that god's help (with the probable exception of Sappho fr. 17), and, in so far as we can tell, it looks beyond the immediate crisis. The order of these main items is fixed: emphasis on danger, request for immediate salvation, imagination of a better future. We can see the basic elements of such a prayer in a narrative episode in Simonides fr. 543, where Danae, after describing to her son the danger implicit in the story, makes a transition to prayer in lines 18-27:

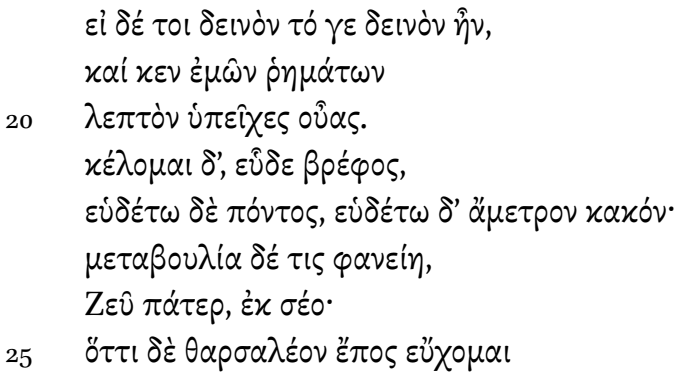

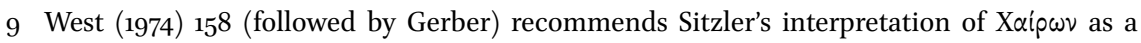
proper name, to avoid redundancy with the following adverb. But there is no redundancy and the word-play is important to the round-trip. However, I can find no way to incorporate in one translation both the meaning 'rejoice in success' (as above) and the use of $\chi \alpha i p \omega \nu$ as the participle of $\chi \alpha \hat{i} \rho \varepsilon:$ 'good-by and good luck'. An even more reduced form of the propemptic

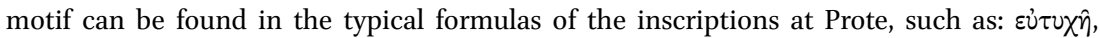

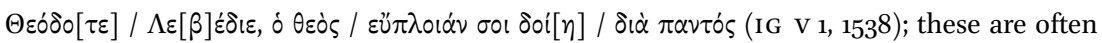
even much simpler, with only $\varepsilon \ddot{\jmath} \pi \lambda \circ\llcorner\alpha$ dative - a reminder that a good voyage comes before success. 


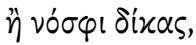

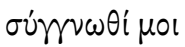

'and if to you what is frightful were frightful,/ you would bend to my words your tender ear./ I bid you, sleep infant,/ and let the sea sleep, and let our measureless evil sleep./ And may some change of will appear, Father Zeus, from you./ And if I make a prayer that is overbold / or without justice, / forgive me.'

Lines 18-20 make the distress prominent, lines 21-22 call for a cessation of the immediate evil, lines $23^{-24}$ call for a complete change in fortune. The god is minimally invoked with an epithet indicating his divine role (although coming from Perseus' mother here it implies a more specific interest). The prayer ends with a routine hope that the god may take no offense at being addressed (here, the negative form of a closing wish for mutual charis).

The songs expressing a wish for safe return that we see in the Lesbian poets are more fully developed versions of these prayers and show three other characteristics. Since these do not appear in the poems in a necessary order, and are given different degrees of emphasis, we can think of them as typical motifs rather than parts of a formal structure. First, and most curiously, although these songs do not adhere to the pattern of cult prayer, they seem to make a reference to prayer or cult practice-past, future, or contemporaneous. Second, they involve helper gods. Prayers to helper gods are common in the Lesbians, but in this group they seem to enjoy a special emphasis. And third, the poems' conclusions, looking to a better future beyond the immediate crisis, appear to incorporate public or civic concerns.

These motifs will be illustrated in a brief analysis of each poem, but the concept of helper gods requires more definition. There are a number of mentions in the Lesbian poets of the general class of daimones - some, children of Zeus; some, lesser divinities - who act in the human realm, generally for mortals' benefit. Their significance may be related to the fact that, apart from his love affairs, Zeus keeps a thunderbolt's distance from humanity. Notice that Danaë does not actually ask Zeus to do anything in the earthly realm, however much that seems to be implied. If a deed must be done, Zeus sends an agent, and these agents are divinities who can also act on their own. As a group, we can refer to them as helper gods, although all gods can help or harm. They are often invoked in formal prayer. The most obvious example of attention to them is Alcaeus' Hymn to the Dioscuri (fr. 34), cited above. His hymn to Hermes also invokes a god who visits humans (fr. 308) and possibly so does his reported Hymn to Hephaestus (Page [1959] 258-261). There is also the opening of a hymn to the 
Hebrus (fr. 45), adapting the elements of the formal invocation to fit an actual river and addressing it as a local deity. Dionysus too can be counted a helper, as

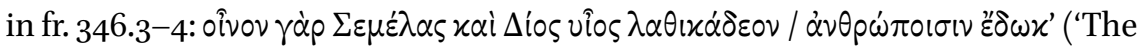
son of Semele and Zeus gave mankind wine as forgetfulness from care').

There are fewer instances of hymns to helpers in the fragments of Sappho, though she apparently has a hymn to Hesperus (fr. 104a), and perhaps to Dawn (fr. 157). The small fragments contain notice of Hermes as wine-pourer (fr. 141.3) and certainly much mention of Eros, Graces, and Muses. ${ }^{10}$ I am not trying to make a case that Lesbian practice is in some way unique, but do want to emphasize that - especially given the sparseness of our fragments-Lesbian song appears to exhibit a strong awareness of the helper gods. They are essential figures in prayers for safety.

\section{Alcaeus fr. 129}

Alcaeus fr. 129 illustrates the form and motifs. The first surviving stanza may or may not be the first of the prayer." ${ }^{11}$ This stanza recalls that in the past the Lesbians established a shrine with altars and gave titles to the gods of the shrine. ${ }^{12}$ The epithets, given in the following stanza, are relevant to the context: Hera, directly addressed by the persona of the singer as 'you', was called

10 See the 'Index Nominum Propriorum' in Voigt's edition. Note in particular Sappho test. 198c, a testimonium from Pausanias, 9.27.3, in a discussion of the genealogies of Eros:

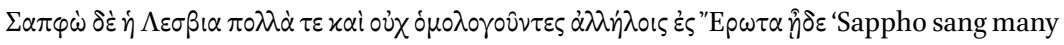
songs to Love that are inconsistent'.

11 Furley and Bremer (2001) rely on a parallel to Sappho fr. 17 to accept Gallavotti's vocative "H $\mathrm{H} \alpha($ sic) in line 1, and then use that circularly to demonstrate the parallel; the emphasis on the festival in the new fragments does support the supposition, but the supplement is not well supported by the papyrus (see app. crit. in Voigt) and is not mentioned by Liberman in his edition (1999). (Liberman has a blank line before $17.1 \mathrm{~V}$, LP, and starts the numbering with line 2. In the absence of the left margin here, nothing can be said about whether or not this is the initial stanza.) By introducing Hera and not clarifying that the verbs in lines 9-12 are plural, the translation in Furley and Bremer (2001) 1.171 gives the incorrect impression that the poem is addressed to her alone.

12 For a discussion of Hera and the precinct see the fundamental article by L. Robert (1960a). More recent bibliography is in the notes on this and the subsequent poems by Liberman (1999) I: XXVI-XXVII, 61-64, and the discussion in Furley and Bremer (2001) 1.172-176, II: 122, who also note the relevance of the epithet. I will assume that one precinct, at the site called Messon in the Roman period and Ta Mesa in the modern period (see Fig. 8.1, p. 199), is referred to in these poems and in Sappho's. See further Nagy (2007b) and Caciagli (2010). Liberman argues that Alc. fr. 129 was actually performed as a prayer but that Alc. fr. 13ob was a reenactment. 
the Aeolian mother of all, or the mother of all Aeolians; Zeus the receiver of supplication; and Dionysus, the third god of the Lesbian trinity or triad (we meet them again in Sappho fr. 17), the eater of raw flesh-a title which becomes all too appropriate when we ultimately discover, later on, Alcaeus' interest in vengeance. By length, vehemence, and position the greatest emphasis falls on Dionysus (lines 5-9):

$$
\begin{aligned}
& 5 \quad x \dot{\alpha} \pi \omega v \dot{u} \mu \alpha c c \alpha \nu \alpha \dot{\nu} v \tau^{\prime} \alpha O \nu \Delta \dot{\alpha} \alpha
\end{aligned}
$$

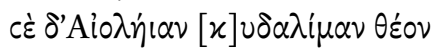

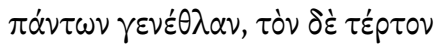

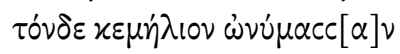

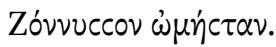

and they called on Zeus as god of suppliants, / and on you, the glorious Aeolian goddess, / as mother of all, and this third one / they named Dionysus Kemêlios, / eater of raw flesh.

Nothing relevant to Hera appears in the rest of the ode. This stanza sounds like an invocation but is in fact part of the historical narrative that describes the founding of the cult. However, it is the de facto invocation for Alcaeus' prayer, because the recitation functions here like the missing formal invocation of the gods that we would expect before the following imperatives asking for their help. The switch from past to present in line 9 without vôv, relying only on $\ddot{\alpha}[\gamma /] \tau(\varepsilon)$, is remarkable. It enhances the formal confusion of the narrated prayer and the performed one. The immediate prayer is for return, the release

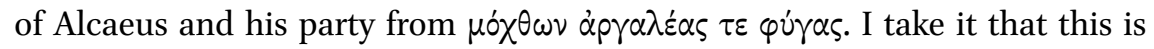
a hendiadys in which the copulative $\tau \varepsilon$ is epexegetic, so that the $\mu \delta^{\prime} \chi 0 \mathrm{ol}$ are specified as the 'pains of harsh exile'. In the narrative that takes up the next four surviving stanzas, no formal mention is made of any relation of the suppliant to the gods or of the gods' past or characteristic interest in the matter at hand. Because the narrative involves oath-breaking, we can infer Zeus' interest, but formally that is only an inference-there is no sanctio or hypomnesis. Without further mention of these gods, Alcaeus then looks past his suffering, and prays that an Erinnys (perhaps in the role of a helper god here) will bring vengeance on Pittacus, who is then expansively accused not only of failing his friends but of destroying the polis. In sum, the structure of the song itself does not have the initial invocation typical of hymnic prayer. Although the body of the poem contains such a prayer implicitly, the basic prayer itself is for a safe return to the city, and the poem moves beyond that to pray for political change. 


\section{Sappho fr. 17}

Sappho fr. 17 has the closest relationship to Alcaeus' poem, but since we lack crucial sections we cannot be sure of its whole structure. Even with the new evidence the restoration — especially of the beginning - remains a thorny problem. (Rather than provide individual notes, I have discussed the textual difficulties of this fragment, and their significance for the interpretation, in a separate chapter in this volume. The following overview relies on that discussion.) Both Sappho's and Alcaeus' poems refer to a cult worship of the Lesbian trinity - Zeus, Hera, and Dionysus - and both call on Hera more directly than on the other two gods. In Sappho fr. 17 she is addressed by name in the second line, and the second person is used for her in a possessive adjective. This initial address is accompanied by potnia, but a full invocation involving genealogy (parents or descendents), haunts or attributes seems improbable. The invocation appears to be minimal, or almost minimal if $\mu \hat{\alpha} \tau \varepsilon \rho$ is supplied in line 1.

In the newly expanded text of Sappho fr. 17 it looks more certain that the poem's emphasis falls on the festival or ritual belonging to the precinct, rather than on the god, even if the relative pronoun in line 3 refers to Hera rather than Éóp $\tau \alpha(v)$. Like Alcaeus fr. 129, Sappho's prayer to Hera features a recounting of a past event, in this case either the founding of the temenos or significant performance of the ritual belonging to it, and Hera plays no special role in the story. The turn away from her is more marked than in Alcaeus' prayer. In a historical narrative that begins with the relative pronoun, Hera is again the addressee, but reduced to 'you', without any expansion, Zeus follows with one brief epithet$\dot{\alpha} v \tau[$ i $\alpha \circ \nu$ fits well—and pride of place goes to the unnamed 'desirable child of Thyone' (no name, but a descriptive epithet and a genealogy)—a supplement that was probable before but is now virtually certain:

10

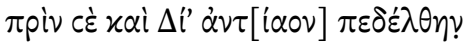

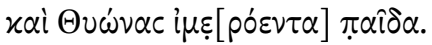

before they approached you, and Zeus of Suppliants, and the desire-arousing child of Thyone.

The ability to be both savage (in Alcaeus) and desirable is of course a characteristic of Dionysus, but the implication here is that he is called on as a welcome god. ${ }^{13}$

13 On the epithets and on the name Thyone, see Caciagli (2010) 229. 
In the sequel, the return to the here-and-now starting in line 11, the performance of a contemporary version of a ritual appears to be described, and at best there is room for a feminine addressee in the gap. The first person plural verb apparently has neuter plural objects, describing the rite, but the activity takes place in a context that also includes a gathering of women:

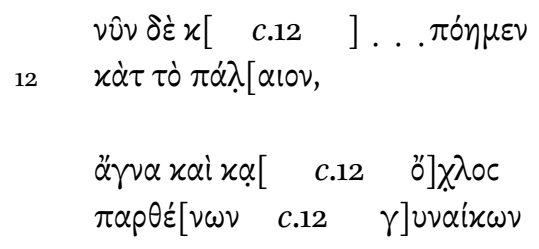

and now .... we perform, in the ancient way, / things holy and .... Throng / of maidens ... of women

So in this poem, there is both past and contemporaneous cult (with a very possible connection to the one in Alcaeus fr. 13ob, where he hears the sound of the women's festival). ${ }^{14}$ Of all the poems this one comes closest to the traditional hymn format, but the absence of fullness in the invocation and the minimal role of Hera in what would be the hypomnesis are telling. Hera is closely associated with storms at sea, and the mythic narrative is concerned with difficulty of travelling by sea, so the song could fit the pattern of a concern for a safe return..$^{15}$ We cannot know what the poem emphasized at its end. Although Hera is (probably) once again addressed in line 20 (the closing line), the emphasis throughout is on the performance of an effective ritual in which she has significant part. It is improbable that this is a cletic prayer, asking for Hera's arrival, because final prayers are usually imperative. It is much more likely that it asks her to insure someone else's safe arrival. Such a safe return may imply, as we shall see below, an erotic theme. ${ }^{16}$

14 The first person plural $\pi \dot{\eta} \eta \varepsilon v$ strongly suggests the presence of a performing chorus. But we do not expect a chorus to be composed of women of differing ages or status, and ó $\chi \lambda \circ$ would be a strange word to use for a chorus. It would not be out of place for describing the multitude at a festival; in Sappho fr. 44.14, which supplies the model for the supplements here, it refers to the crowd who look on at the procession of Hector and Andromache into the city.

15 For the literary evidence and the relevant literature on Hera and sea travel, see Lidov (2004), and for more valuable archeological evidence see de Polignac (1997) (I am grateful to Prof. Boedeker for bringing this to my attention), and Boedeker, this volume.

16 I do not mean to deprecate the importance of Hera to Sappho or to the ceremony for which 


\section{Sappho fr. 5}

I have already outlined the differences between fr. 5 and the standard prayer form. $\dot{\alpha} \beta \lambda \dot{\alpha} \beta \eta[v$ in the first line, and the fact of a prayer to the Nereids-a simple

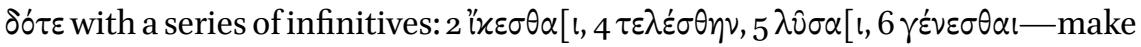
clear the danger of sea-travel and the desire for the 'brother' to be free of it. Since the Nereids can be considered helper gods, and are not presented as having any other function here but to help, the emphasis on the danger and the request for safety overlap. The language for his happy arrival, as I noted above, belongs to the motifs of propemptica. Here it is expanded in a familiar way: his friends will be glad to see him, his enemies will not. After the imperative prayer, the mood shifts to an optative of wish, and the conventional topics signal the desired state of affairs once the brother figure arrives, as the persona of the singer hopes that 'we' have no $\varepsilon^{\prime} \chi 0$ ós, and goes on to hope that the 'sister' will have greater honor. ${ }^{17}$

she composed the poem, only to point out that formally the poem does not conform to the hymnic tradition that foregrounds the god. Furley and Bremmer (2001), despite their insistence on the importance of naming (I:52) and of the imperative (I:61), write of this fragment that 'all the elements of a typical cletic hymn are there' (I:165). Their analysis, which relies on significant supplements to the previously published texts, includes the imperative translation 'come to my aid' as interpretation of the final traces, where only the infinitive is possible. The subject of the infinitive is more likely to be in the previous

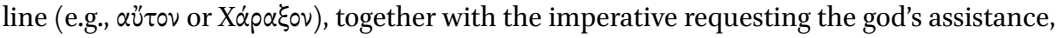
or (as in Danaë's prayer) a third or second person optative addressed to the god. Pindar, Ol. 6 and Pyth. 8 conclude with imperative prayers for a safe voyage; Nem. 9 has an عüxoual + infinitive construction, but the prayer, to Zeus, is for the poet's own future success and not for any direct action on the god's part.

17 For a wish for one person's greater honor as an ordinary part of prayer for success,

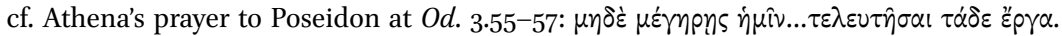

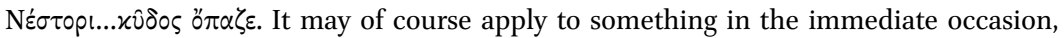
but it need not. West (2014) 5 with $n$. 11 cites the interpretation of lines 7-8 given above from the editio princeps without accepting it. The readings he allows either understand हî to refer to the feminine oví $\alpha$ or take it as an indefinite ('anyone') with 'brother' as the subject of $\gamma \varepsilon$ vo

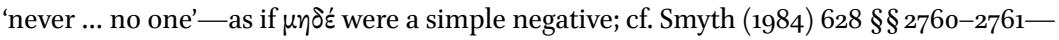
and also expects 'brother' to be the subject. But what West calls a 'series of wishes' is in fact articulated into two series by the change of mood in this clause, so that this verb

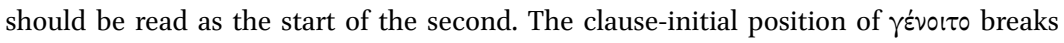
the continuity of the 'brother' as topic, and, together with the general expectation that initial verbs of being have the sense of 'there is', indicates that the new sequence begins with an impersonal construction. In the next stanza the initial, specifying article of line 9 , repeating the structure of line 2 , reintroduces the personal constructions. 
Recent comments on this poem, perhaps under the influence of Page's commentary, have taken for granted that it reflects Herodotus' story about Charaxos' improvident dealings with a notorious prostitute, identified by Athenaeus (test. 15 Campbell) with a Doricha whose name must have been found in Sappho's poems. Previous scholarship had also seen that the content might be political. Attempts to supplement and interpret the gaps followed from whichever assumption was made. ${ }^{18}$ But such a method disguises the motifs and structure, and any decision about reference should be postponed as long as we can clarify the poem without one. For example, we know the poem has 'brother' and 'sister' (my warning in Lidov 2004 has become pointless), but in view of the Charaxos poem, in which two people (whoever they are) discuss two others (or one other if we take Larichos to be the addressee), we should not assume that the persona of this song is identifying herself as the 'sister'. (Indeed, the most natural interpretation of two third-person references is that neither is the speaker.) The persona here could be that of a parent or another brother, even without relinquishing the traditional biography.

Haste has particularly affected the interpretation of $\ddot{\alpha} \mu \beta p o \tau \varepsilon$ in line 5. Generally, when someone prays to a god, he or she fears that the god's displeasure may be or may have been incurred, and asks to be released from any inadvertent offense. This is how Danaë, quoted above, ends her prayer. It is unlikely that someone petitioning on another's behalf would concern the god with the offense the other has done to him- or herself. In Iliad 24.68, the word for failing in one's duties to a god is $\dot{\alpha} \mu \alpha \rho \tau \alpha \dot{v} v \omega$ : Zeus says he is fond of Hector, $\dot{\varepsilon} \pi \varepsilon \dot{~ o v ่ ~} \tau \iota$ $\varphi i \lambda \omega \nu \dot{\eta} \mu \dot{\alpha} \rho \tau \alpha \nu \varepsilon \delta \dot{\omega} \rho \omega \nu$. The normal form of releasing yourself from retribution by a god whom you may have offended, or would offend by not giving thanks, is sacrifice. The Nereids in particular are gods to whom travellers sacrifice, and this may have a particular resonance on Lesbos. Although modern commentaries state that there was a cult of Nereids on Lesbos, there is no special evidence for a contemporaneous cult (Pausanias 2.1.8 suggests that the worship was widespread on the shores and islands of the Aegean). The evidence specific to Lesbos is a legend that the original founders were instructed on arrival to make a sacrifice to Poseidon and to Amphitrite and the Nereids; the latter sacrifice was to be of a maiden, who, in one version, becomes a Nereid. ${ }^{19}$ So

18 Ferrari (2014) 4-9 makes clear that he assumes Herodotus' story as a basis and his textual and interpretive commentary illustrate the consequences; West (2014) is not different. The alternate tradition goes back to Wilamowitz; there is a summary of the theories in Saake (1972) 104-107. For an example of the consequences of starting from the assumption of a political reading, see Schubart (1948) 313-314.

FGrH $477 \mathrm{~F} 14$ and (for the Nereid) FGrH $140 \mathrm{~F}$ 4; the story mostly concerns the lovelorn 
there may well be an allusion here to historical cult practice, and there is good reason why it should be only an allusion. This portion of the prayer, ö $\sigma \sigma \alpha . . . \lambda \hat{v} \sigma \alpha \mathrm{l}$, within the imperative sentence, may reflect a desire that the brother be able to perform the rituals that are part of the conditions of a happy return.

In the gaps after line 10 it is impossible to know precisely what is going on, but reference to some kind of local worship would not be out of place. We have already seen it in fr. 17, the prayer to Hera. But before I discuss this further, it will be useful to bring in another text which offers possible parallels to several motifs in this poem. In Euripides Helen, 1451-1511, the chorus wish good speed to Helen as she returns home (a clear instance of a propemptic prayer for a traveller leaving for home). They begin with a wish that the Nereid Galateia (here the daughter of Pontus, but elsewhere of Nereus, the son of Pontos [Gantz (1993) 16-17]) ease her journey (strophe A), and then they imagine her arrival, when she will join ongoing festivals and find her daughter still unwed (antistrophe A). After wishing they could follow her like birds (strophe B), the chorus end the ode with prayer that when she has arrived, her divine brothers will free her from the $\delta \dot{v} \sigma \chi \lambda \varepsilon \_\alpha$ of adultery caused by her absence (antistrophe B). ${ }^{20}$

In fr. 5 , a description of a return home to the welcome of a ritual may occupy lines 10-14:

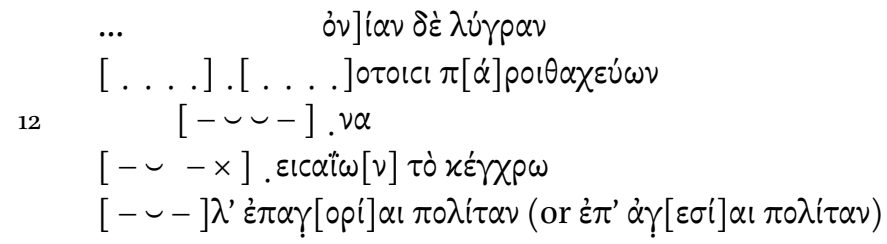

youth who dived in after her. The fullest narrative is in Plut. Conv. sept. sap., 20. On Nereids see Barringer (1995) 55 with n. 7 et passim; Csapo (2003). Shields (1917) reports no evidence of cult.

20 For a discussion of the propemptic motives, see Kannicht (1968) 374 with n. 1. For an analysis of Dionysiac motives, as part of the structure of the whole, see Steiner (2011) 301-303. Steiner also draws attention to the choral character of Helen's imagined escorts, with the implicit self-reference to the chorus's own performance as well as to imputed past performances. The parallel would continue to hold if the appeal to the Nereids here is understood as belonging to the same kind of ceremony that is implicit in fr. 17 and the Charaxos poem (I thank Professor Bierl for bringing this to my attention); we might also consider whether there was a chorus for this song who mimed the mythical chorus of Nereids encircling a boat, so that the appeal was enacted in the performance itself. 
The masculine participles $(\alpha) \chi \varepsilon \dot{v} \omega \nu$ and $\varepsilon i \sigma \alpha i i \omega[\nu$ must refer to the 'brother'. The most likely division in line 11 is $\pi[\dot{\alpha}]$ por $\theta$ ' $\alpha \chi \varepsilon \dot{\omega} \omega \nu$, 'previously suffering a cruel agony'.21 The preceding dative would most likely be a dative of cause or of means (with oviav): since one typically suffers at the hands of the god,

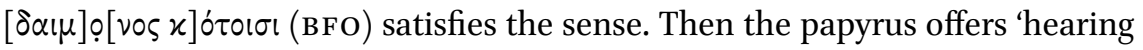
the [...] of the millet seed' so 'sound' needs to be supplied somewhere: xpov̂ $\alpha$ would fit at the start of both lines 13 or 14, but since a verbal structure to govern the dative in 14 is needed, the former seems preferable. There is nothing to indicate whether the two participles are each attached to separate finite verbs or are parts of a compound phrase. As the editors point out (Burris, Fish, and Obbink [2014] ad loc.) the sound of the millet seed figures in a paradox of Zeno, and so it must have become in some way proverbial. The instrument in question would have been some kind of manufactured rattle, or perhaps just the seed noisily poured back and forth between two containers. West points out that non-musical noise makers, such as rattles, were used to create excitement, and were particularly used in 'orgiastic' cults $([1992] 122,126)$. This leads us to the question of a Dionysian ambience in these poems, to which

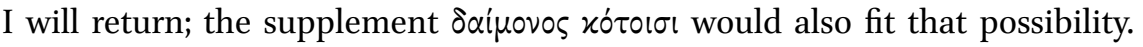
The textual difficulties are real, but are probably made more difficult by a predetermination that the poem must verify Herodotus' and Athenaeus' stories of Charaxos' misbehavior. ${ }^{22}$

21 The stem $\chi \varepsilon \dot{\varepsilon}$-, "pour" (without a sigma), is found only for the epic future and aorist in archaic and classical Greek. It is aorist in Alc. fr. 362.3, and can be aorist in Sappho fr. 96.27. It takes an internal object, which makes it hard to construe with óviav. The active $\dot{\alpha} \chi \varepsilon \dot{v} \omega$ does not take an object (except in the forms that have a causative sense), but ovía here can be construed as an internal accusative (as translated by Obbink, ch. 1, this volume).

The switch to a past tense in line 15 interrupts the progression from the optative verbs in lines 7 and 9 to the final wish and has to be accommodated by some complication. However, West is wrong, in his commentary on these lines ([2014] 9-7), to label the interpretation of millet seed given above 'bizarre fantasies'. Given that the word is adjacent to a verb of hearing and that millet seed is associated with sound in the later parodox, something to do with noise is in fact the default reading. Rattles containing seeds need no comment (by chance I noticed from a much earlier date two large bronze Hittite pins, essentially rattle shaped, with poppy-flower shaped heads containing rattling 'seeds' [New York, Metropolitan Museum, accession number 1989.281.14 and 1989.281.15]). The alternative reading, $x^{\prime} \dot{\varepsilon} \gamma \chi \rho \hat{\omega}\langle\iota\rangle$, supposing both an elision and an omitted letter, which West and Ferrari prefer, requires a metaphorical or figurative use of injury from a razor that is out of keeping with the diction of the poem, which has been quite plain, and that has the further disadvantage of not being well established until later (and rarely without some actual reference to either a razor or a scraping motion; if the singing persona is 
The innocence of Helen is, of course, what the Helen is about, and so the concern for her reputation cannot be taken as a pointer to erotic themes in fr. 5 , although it also does not speak against them. $\varphi$ i $\lambda$ os and $\tau \mu \eta \dot{n}$ (the opposite of $\alpha i \delta \omega \varsigma)$ can have meanings in the spheres of both private and public life.

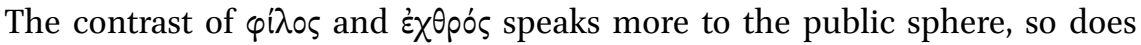
the 'censure (or 'leadership') of the citizens'. ${ }^{23}$ It is notable that the only two uses of $\pi 0 \lambda$ i $\tau$ '

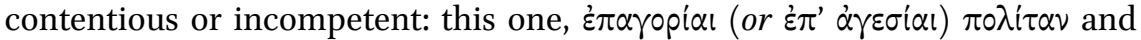
$\tau \hat{\omega} \nu[\dot{\alpha}] \lambda \lambda \alpha \lambda \circ x \dot{\alpha} x \omega \nu \pi 0 \lambda i \tau \alpha \nu$ in Alc. 13ob.7, the other poem describing his exile. They no doubt exhibited such behavior over a number of issues, so reference to it does not dictate one or another particular circumstance here, but the vocabulary certainly indicates that the turn toward the public sphere, which I suggested is part of the form, does occur. For anyone looking for a reading that reflects the biographical tradition, a reference to a return from the Sicilian exile is as likely as one to Charaxos' activities in Egypt.

Line 15 is especially obscure. For the difficult traces at the beginning neither West's $(1914,6)$ reading of $\alpha$ - $\mathrm{a}$ conjunction or the feminine plural nomina-

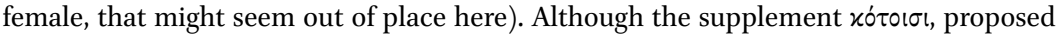
in Burris, Fish, and Obbink, is an unexampled plural (as West notes), as a type of plural it is quite normal, the manifestations of the idea expressed by the singular (cf. Smyth $\S 1000(3))$. To provide an alternative to $x \dot{\varepsilon} \gamma x \rho \omega$ and to a unique use of the plural of

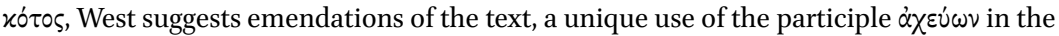
causative sense (that meaning is normally found with other stems from the same root), the supplement of a tell-tale first person pronoun and a proper name, and a particularly complex and obscure contrary-to-fact syntax to accommodate the thought sequence: 'And may he see fit to treat his sister with greater respect; may he [release me] from the grim pains with which in the past he grieved and [overcame my heart,] hearkening [the while to Doricha,] which would now be p[lucking me] to the raw through the censure of the townsfolk, just as much as ever; but it was not long before he came to realize it'. This has the advantage of connecting the poem to Ovid[?]'s elaboration of Herodotus' story and Athenaeus' correction of it.

23 Lobel's suggested supplement $\dot{\varepsilon} \pi \alpha \gamma\left[o \mathbf{p}^{i}\right] \alpha \mathrm{l}$ (the accent survives, guaranteeing the dative singular) is widely accepted, but in fact not printed in either Lobel-Page or Voigt. Voigt considers it doubtful. The word is conjectured as a correction to the text of Pindar fr. 22.6, and otherwise is not known until it is used by late Imperial historians. A related verb form, $\dot{\varepsilon} \pi \eta \gamma o p \varepsilon(\dot{v}) \omega$ occurs once in Herodotus (1.90.2), when Croesus seeks permission to challenge Apollo for betraying his friend, and Cyrus asks with what he will charge the

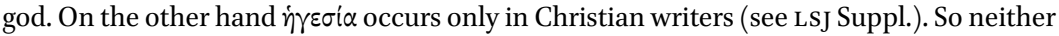
conjecture is well founded, but the first may be slightly more probable. Prudish readers have imputed a censure of sexual irregularity to the word in the Pindar fragment, but it would be prudent not to transfer an inference based on a conjecture to the text of Sappho. 
tive relative pronoun (the dative would have a tau)—nor $\eta$ (Burris, Fish, and Obbink), however interpreted and probably too narrow, are especially convincing. The best reading appears now to be:

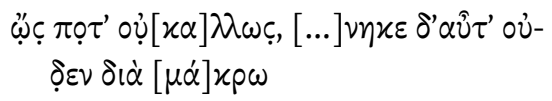

Although the sequence $-\lambda \lambda \omega \varsigma$ could be an elided third person verb (singular indicative of the Aeolic - $\omega \mu$ type or plural subjunctive of any type), no convincing possibilities present themselves. It is most likely to be the adverb $\alpha \lambda \lambda \omega \varsigma$ in the letter sequence $\circ v[x \alpha] \lambda \lambda \omega \varsigma$. This allows three different articulations: $00 x$

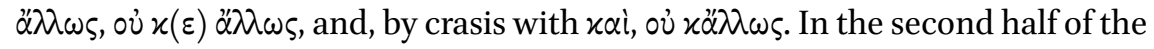
line the sequence $-v \eta x \varepsilon$ invites a verb as supplement: an imperative, a perfect or aorist active third person singular indicative ending in $-\eta \chi \varepsilon$, or an imperfect of an Aeolic $-\eta \mu$ เ verb with $x \varepsilon$. Editors focussing on a supposed failure and

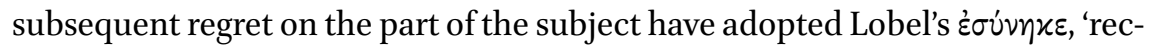
ognized'. ${ }^{24}$ A verb appropriate to the context without any suppositions would be ह่ $\pi \alpha v \eta^{\prime} \varkappa \omega$, 'have come back, return, be back'. ${ }^{25}$ The simple verb may occur in Sappho fr. 114.2 (the quotation is apparently corrupt) and occurs twice in Homer; this compound does not appear before the end of the fifth century and it is not very common after that. Nonetheless, there are indirect indications that it may be an appropriate word for this passage.

24 The position of the augment is justified by a gloss, Alc. fr. 408. The words $\sigma v v i \eta \mu \iota$ and $\alpha \lambda \lambda \omega \varsigma$ (unless $\dot{\alpha}^{\prime} \lambda \lambda^{\prime} \dot{\omega} \varsigma$ ) are in successive lines in Alc. fr. 58, but the context emphasizes drinking and nothing indicates that they are part of the same construction (confusion with $\alpha \lambda \omega \omega$ s = $\dot{\eta} \lambda \varepsilon \hat{\omega} \varsigma$ is also always possible; see app. crit. to Inc. Auct. 5). The interpretation with $\sigma v v i \eta \mu$ offers no gain in simplicity, and leaves me wondering what the (errant?) brother realized, and where and when he realized it (reading $\alpha \hat{\tau} \tau^{\prime}$ as an elided neuter singular or plural accusative makes it no clearer). Sappho can refer to people without being specific (as in fr. 1) or may refer to what the audience had prior knowledge of (as in fr. 17), or may allude to a literary or religious tradition (as in the opening of fr. 16 , or the possible reference to the sacrifice to the Nereids here), but she is not reticent or evasive (we need to know that Anactoria is absent, and she tells us; the surviving text of both fr. 5 and the Charaxos poem

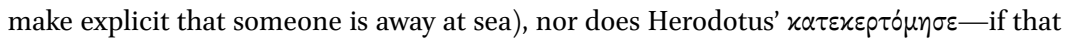
passage is to be taken as a guide-suggest any such restraint in her supposed discussion of her brother's misbehavior.

25 Obbink, in his discussion of the Charaxos poem (ch. 9, this volume), points to the frequency with which words for 'come, go' are associated with him (i.e., with the brother

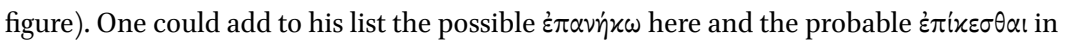
fr. 17.20 . 
In the last sentence of the transmitted text of the Iphigenia in Aulis, lines 1627-1629 (the editors, since Porson, consider the passage part of a late addition to a damaged or incomplete text), the chorus addresses Agamemnon with a propemptic wish for his voyage out and back:

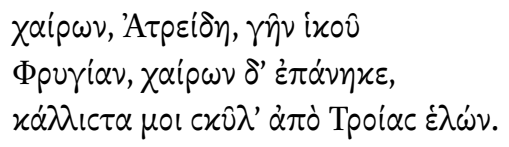

Go rejoicing, son of Atreus, to the land of the Phrygians and return rejoicing, having taken fair spoils from Troy.

tr. KOVACKS

These lines contain motifs similar to those of Theognidea 691-692, quoted above. The word also occurs in a passage attributed to Hellanicus of Lesbos

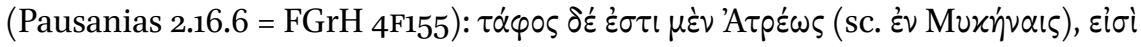

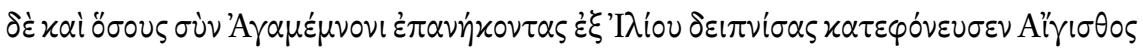
('the tomb of Atreus is there, and of all those whom Aegisthus killed at a dinner when they returned from Ilium with Agamemnon'). However mediocre the composer of the close of the $I A$ was as a poet, there is no reason to suppose that he was ignorant of the literary tradition into which he meant to insert these lines, and the coincidence of the context for the two uses-although they are sufficiently dissimilar to preclude a direct borrowing - points to an earlier poetic tradition which made the verb ह̇ $\pi \alpha v \dot{\eta} x \omega$ available as a key term for a nostos, especially Agamemnon's. ${ }^{26}$ In particular, the sense of a return from a distant journey with cargo (not excluding a bride figure) is appropriate here, and reference to the much-delayed Achaean nostoi would give a special

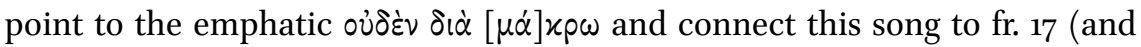

26 West (2011) 325 with n. 29, concludes that evidence in the text shows that the composer was a 'student of Euripides who possessed some familiarity with tragic language,' shows knowledge of Sophocles, and had studied works of the metricians. The only other poetic uses of ż $\pi \alpha \eta \dot{\eta} \kappa \omega$ are in Plato Comicus, Lakones, fr. 70 K.-A. (as emended), to refer to the soul of Aesop coming back from the dead-a nostos of sorts, but there is no context and

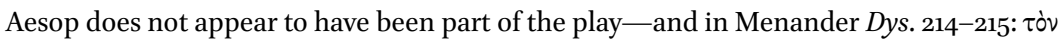

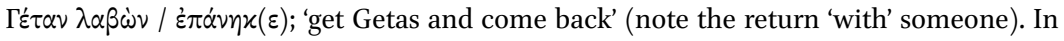
prose authors, mostly post-classical, the verb is used for 'come back, come home'. There is a rhetorical metaphor in Pl. Phdr. 246a4, $\pi \dot{\alpha} \lambda \iota v \ldots \circ \dot{\jmath} x \dot{\varepsilon} \pi \alpha v \hat{\eta} x \varepsilon$ to describe a speaker who does not turn back from a topic until he has properly exhausted it. 
less directly, to the allusions to Odysseus' nostos in the Charaxos poem). ${ }^{27}$ The evidence for such a tradition balances the argument against supplementing even a compound that is only found in later Greek. ${ }^{28}$

In Alcaeus fr. $129.18 \omega \varsigma \pi \circ \tau^{\prime}$ followed by a past indicative verb introduces a narrative explanation of the reasons for his prayer; the context is different here but a single clause of explanation or expansion, using the one verb, would be in a parallel position. At first glance that could produce a line referring to the conditions of the brother's return (adjusting for the Aeolic spelling of - $\alpha \nu$-):

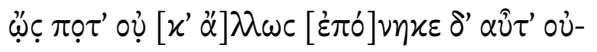

ọ̀ेv $\delta ı \dot{\alpha}[\mu \dot{\alpha}] x \rho \omega$

Since he would not ever in another way have come back again at all after a long time ( or soon $^{29}$ )

But there is probably an insuperable obstacle in $\delta^{\prime} \alpha \hat{\tau} \tau \varepsilon$. The elided delta (which is in the papyrus) would have to represent $\delta \dot{\eta}$ and that combination is uniformly spelled $\delta \eta v \tau \varepsilon$ in the papyri of the Lesbians (the secondary tradition is less consistent). In addition, both $\delta \dot{\varepsilon}$ and $\delta \eta \hat{\tau} \tau \varepsilon$ follow the first constituent in Sappho, and the Homeric uses of $\alpha \lambda \lambda \omega \varsigma$ (which is not found elsewhere in Sappho)

27 There is a different possible allusion to the myths of the Atreids in the brother who returns 'to give his [unmarried] sister greater honor'; the story of Orestes and Electra also involves the stopping of an 'unendurable evil' and at least in Euripides it ends in a marriage. One need not decide whether the 'brother' here is being compared to Agamemnon or Orestes; these are allusions, or what L. Kurke in this volume calls 'mythic models', not narrative, mythic analogues, and they give a color of significance to the occasion. The role of brothersister relationships in these poems is discussed particularly by A. Peponi (with reference to Orestes and Electra) and G. Nagy in this volume, and Kurke draws attention to a possible allusion to the Dioscuri in the Charaxos poem on the basis of the same ode from the Helen that I have discussed above in connection to fr. 5 .

28 There remains the possibility of reading the Aeolic imperfect of $\pi \circ v \varepsilon$ É , and combining a potential optative, asserting the inevitability of a triumphal homecoming, in the first

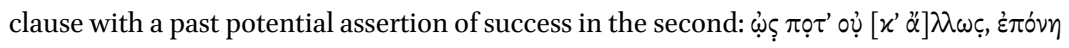

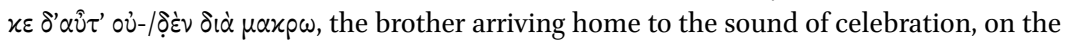
one hand overcame the objection (or assumed the leadership) of the citizens, 'as could not ever be otherwise. And after all (= on the other hand, even if he were suffering now), he would be suffering nothing in the long run'. But the sequence $x \varepsilon \delta \varepsilon$ is doubtful (as Prof. Lardinois has pointed out to me) and the syntax is strained.

29 Or, with ởx $\ddot{\alpha} \lambda \omega \omega$, 'since he did not ever come back again in vain after any long time'. For the litotes ov่ộ̀v $\delta \dot{\alpha}[\mu \dot{\alpha}] x \rho \omega$, see West (2014) 6 . 
scarcely allow even the option that it is part of a quasi-prepositive adverbial string included in that constituent (see the separate discussion of fr. 17.4). So there must be two clauses here, the second with $\delta(\varepsilon)$ (there is a comparable structure in lines 7-8). The first part of the line would belong to the previous sentence, and its verb would be inferred from the previous clause. But the sense of that is unknown, and, in addition, the idioms of $\alpha \lambda \lambda \omega \varsigma$ are too varied to provide any direction. Among possibilities as diverse as 'as once not in vain' and 'as could never be otherwise,' I find it difficult to make a specific suggestion.

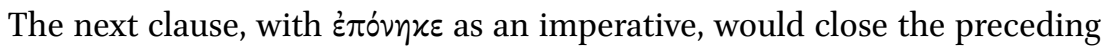
wish with a restatement directly addressed to the (absent) brother: 'come back again after no long time'. Such an imperative could also be, in transition, the foil to a new, capping crescendo, introduced by the vocative and particle cù $[\delta] \grave{\xi}$ Kú $\pi[p]$, and concluded by an imperative prayer in the next stanza.

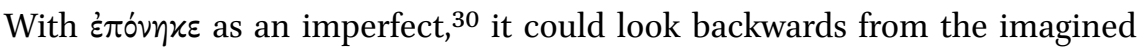
future return in triumph: 'but he had come back again after no long time' orwhat seems to me more likely - could compare the present occasion to other occasions for such songs, or other performances of the same ritual. Just as fr. 1 recalls a prior prayer to Aphrodite (such as the Kypris song), and the Charaxos poem implies the performance of a prayer to Hera such as is found in fr. 17, so this could refer to another song about the safe return of a 'brother' (perhaps fr. 15 would be an example of the type; note that these examples are all within the short, surviving segment of the alphabetic sequence and are unlikely to be unique cross-references). Then $\delta^{\prime} \alpha \hat{v} \tau^{\prime}(\varepsilon)$ would function much like $\delta \eta \hat{\tau} \tau \varepsilon$ in fr. 1, but without the tone of impatience. This gives the approximate sense, '... to/by the censure/leadership of the citizens, as once no differently. And he was home again after no long time'. Such attention to repetition, a form of generic self-reference, could serve to enhance the present performance by drawing attention to its participation in the community's history of performance. ${ }^{31}$

The invocation to Kypris in the final surviving stanza, which may or may not be the last of the poem, can belong to different general interpretations. A reference to marriage as a public event is as likely as a reference to private sexual attraction. Reference to marriage or to a marriageable person, direct or oblique, seems to be a typical motif of a return. We see it in the Odyssey, of to Prof. Lardinois for a discussion of the possible meanings of an historic tense here. Obbink (2011) 33-38 and ch. 9, this volume. Note in particular that "always" in line 5(1) of the Brothers song could suggest other songs of complaint or (if taken with the infinitive) other occasions of return, rather than just be a dramatic fiction. 
course, in the person of Telemachus, the ruse after the suitors are slain, and the reunion; it also occurs explicitly ( $\pi$ o $\gamma \alpha \dot{\alpha} \mu \omega \nu$ ) in the reference to Hermione in the Helen stasimon (lines 1476-1477); and it looks probable in the Charaxos poem. (Alcaeus' poem has other concerns.) As a practical matter, marriage could be part of a reconciliation that ends exile. ${ }^{32}$ Apparently Kypris' intervention includes taking action, $] \theta \varepsilon \mu[\varepsilon \dot{\varepsilon} v] \alpha$, in regard to some evil. The participle needs an object, and because the new addition of ouxxov. [ at the start of line 19 reduces the available space, it would be difficult to have in addition a separate object for the verb of the sentence; so the latter is most likely to be a request for favor. To illustrate this I suggested in Burris, Fish, and Obbink (2014):

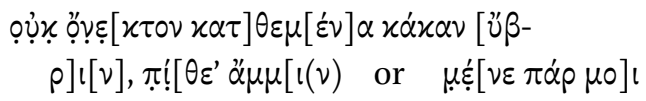

Putting a halt to an unendurable outrage, give us your assistance. ${ }^{33}$

32 Cf. Hdt. 1.6o-61, on Pisistratus.

33 This is, of course, speculative. Perhaps Kypris is being asked to impose some evil (I have not seen any such supplement proposed, but it would conform to the common reading of fr. 15 as an attack on Doricha!). In my suggested supplement, ợ the adjective can be attributive ("halting an unendurable evil offense") or predicative ("rendering an evil offense not unendurable"). The supplements recorded by Voigt, offered when there was no knowledge of the start of line 19, assumed that $x \dot{\alpha} x \alpha \nu$ introduced the object of the verb that would be in line 20, rather than of the participle. My own suggestion, $u ̈ \beta-/ p v v$, is a variant of Milne's šp $p v$, intended to bring out the potential of personal, erotic and the public implications in the earlier vocabulary, as well as to provide a term forceful enough to justify the enjambment of an uncompounded single lexical word. West (2014) 7 points to the possibility of avoiding enjambment by placing an enclitic for at the end of the line, but the postponement of an enclitic to a position after two or three constituents in the same phonological phrase is unlikely (see my separate discussion of fr. 17.4 in ch. 19 in this volume in regard to the placement of enclitic pronouns). And although as a general rule it is preferable to normalize the rhythm (such overruns are a small minority), this line is already rhythmically unusual, because it contains the only disyllable in the ninth and tenth positions: that is, $x \dot{\alpha} \kappa \alpha \nu$, for which there is no alternative, contravenes the rule that the rhythm ... $\checkmark-/ \cup-/-$ is avoided at the end of all three hendecasyllables in the stanza. (Perhaps the rule arises from a desire to avoid reinforcing a misperception of a blunt cadence. I do not count Sappho fr. 39.1, which relies on one possible emendation of a prose quotation; it may belong to a different meter [see Lidov (2004) 396 with nn. 14-15; I add that the line would likely be preceded by a dative $+\delta \dot{\varepsilon}$ but withdraw the suggestion of $\alpha x \alpha \dot{x} \alpha \nu$ for this line]). The middle participle is also unusual, since it is the only certain example of one outside of fr. 2 (the use in fr. 2 is discussed below). 
The important point is that the poem as we have it appears to exhibit the form of a prayer for safe return, and that such a prayer can suit more than one occasion. Although there is room for a case of the proper names either Doricha or Larichos in line 13 (but not for Charaxos anywhere), the sensible course is probably to respect the poem's initial use of family signifiers-'brother' and 'sister'-rather than proper names, and not try to specify the occasion that justified the form.

\section{Sappho fr. 15}

The mention of Kypris connects the Nereid song to Sappho fr. 15. Although the new fragments do not contribute to it, some account of the possible parallel is required (the fragment is part of POxy 1231, which also contains previously known portions of fragments 16, 16a, and 17). Two papyrus pieces are assigned to the poem, one including a final stanza, lines 9-12, addressing Kypris. In this case the totally new subject in 16.1, following directly on the papyrus, makes it very likely that this is the last stanza of the song. ${ }^{34}$ The preceding lines contain letters that could be supplemented to make a close parallel with the Nereid poem, as in Ferrari's reconstruction ([2014] 10), following Fränkel, of the stanza immediately preceding the naming of Kypris:

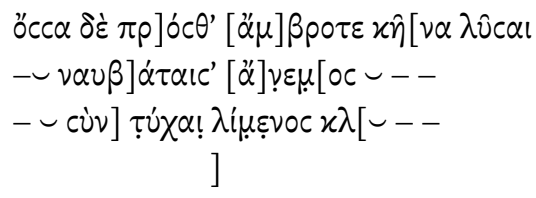

those things that he got wrong, ... release / ... sailors(?) wind ... / with good fortune (or: attainment of) harbor ...

This parallel is very speculative, both in terms of the readings and the placement of the papyrus fragments. It reflects the expectation that the invocation of Kypris in the following stanza is a manifestation of the same type of prayer as the Nereid poem, because it too can be made to refer to Athenaeus' correction of Herodotus' narrative by reading Doricha in the stanza's third line:

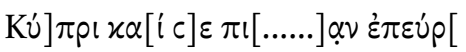

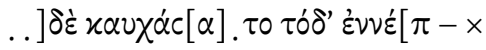

34 In general, Voigt's texts do not always make clear when a coronis is in the papyrus or is an editorial supplement. 


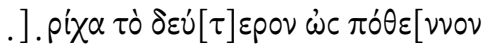 \\ 12 $-]$ हैpov $\hat{\eta} \lambda \theta \varepsilon$.}

Kypris, and ... find you [...] / and ... claim or boast this say ... / ...richa second (time?) that desirable ... came.

Modern commentaries take the reference for granted, so I have provided a largely unsupplemented version here to illustrate how much the text does not speak for itself. The first line could be a wish or a narrative (the only certain verb ending in the stanza, the last word, is an aorist indicative), since the verb could be any number of the singular or the third plural in the indicative, or second or third singular in the optative; the second line could begin with the negative ovj] $\delta \dot{\varepsilon}$ or with the relatives $0^{\prime}$ '] or $\left.\alpha{ }^{\prime \prime}\right]$, and the verb could be third singular optative or third plural indicative (the two missing syllables of the final participle can be adjusted to anything except a masculine singular). For the adjective in the first

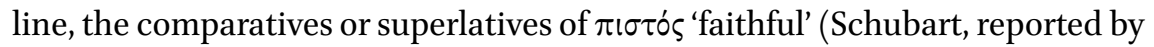

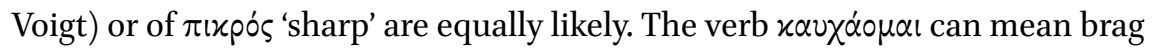
(obnoxiously) or boast (proudly and legitimately). The ending of the first word of the third line is most probably a name in the nominative (and not a third declension accusative singular), but $\Delta] \omega \rho^{\prime} \chi \alpha$ fits the trace very badly (if at all). ${ }^{35}$ If $\delta \varepsilon \dot{\tau} \tau \varepsilon \rho o v$ is negated, it can be a litotes: 'not second' is first, emphasizing the immediate occurrence, i.e., 'May -richa boast saying this just once, that ...' with the negative, as usual, attaching itself to the main verb. ${ }^{36}$ We can reconstruct very little, but if this is a prayer for safe return, it seems as likely that both poems end with a wish for success in the marital sphere of civic life, as that one or the other ends with a particularly vicious imprecation of someone who loves or

35 I have discussed the 'Doricha' story at length in Lidov (2002). The essential point has to do not with whether or not Doricha can be read here, but whether the post-Herodotean prose authors are independently consulting the text of Sappho or are working with the text of Herodotus and, especially, the (sometimes hostile) commentaries and secondary material based on it that incorporate an inventive Hellenistic biographical tradition. Pace Dale (2011) $67 \mathrm{n} .73$, it is clear from a full review of the contexts that Athenaeus consistently derives his information about Sappho's brothers from such other sources and not from a reading of a text of her poems (which, moreover, contrary to his normal practice, he never quotes on this subject).

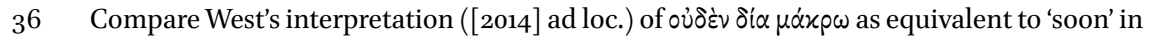

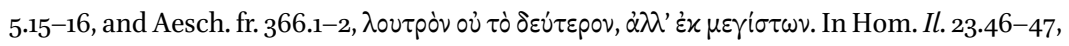

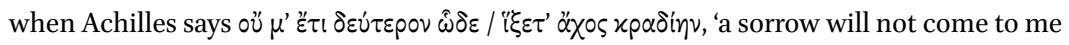
in this way a second time', he is not really thinking about the future. 
is loved. Whatever the goal, Kypris may be described as taking an active role. Other poems may clarify Sappho's conception of her, but this fragment itself offers no further evidence. ${ }^{37}$

\section{The Charaxos Song}

I will discuss the language and structure of the Charaxos poem as a composition further below. For now I want only to show that it conforms to the pattern of prayers for safe return that I have proposed.

We lack the actual beginning but it must have been an introduction to what we do have, a dialogic situation featuring an 'I' and a 'you'. ${ }^{38}$ It is clear that the problem is the travel of Charaxos at sea, and the uncertainties that attend his absence. The dialogue turns to offering a prayer to Hera; there is no specific reference to cult, but $\pi \dot{\varepsilon} \mu \pi \eta \nu$ implies a ceremonial movement, and Hera is addressed as $\beta \alpha \sigma^{i} \lambda \varepsilon i \alpha$, which looks like a cult title (Zeus is $\beta \alpha \sigma^{i} \lambda \varepsilon v \varsigma$ below, and a reference to a $\tau \varepsilon i \chi \chi 0 \varsigma \beta \alpha \sigma i \lambda \eta^{\prime}$ ov at Alc. 130a.15 is explained by a scholion as the one 'of Hera'). ${ }^{39}$ No additional reason is specified for making Hera the object of the prayer. As a prayer, it is much like the one in the stanza addressing the Nereids in fr. 5: a bare address to a power to assist in the arrival of the traveller. We are made aware that a disaster is feared, and hear the hope that it will be averted. The identification of the prayer here marks it as a general cult type. The absence of article or possessive adjective with $\nu \hat{\alpha} \alpha$ in line 12 (8) means that it is 'a ship', not grammatically a reference to the ship of line 6 (2). The addition $\chi \not \alpha \mu \mu$ ' $\dot{\pi} \pi \varepsilon \dot{v} p \eta \nu \dot{\alpha} \rho \tau \varepsilon \mu \varepsilon^{\prime} \alpha \varsigma$ is otiose in this context (unless this is a prayer for a very distant future - their own current state is known to them); it corresponds to

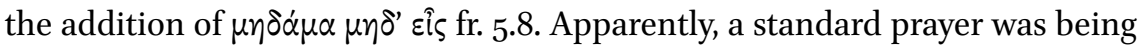
identified by its key words: we could paraphrase, 'address to Hera the prayer to bring the traveller home safely and find his family safe' ${ }^{40}$ But this prayer will

37 The possibility that $\eta \lambda \theta \varepsilon$ here may refer to the experience of the traveller and have erotic connotations is another reason not to assume that the end of fr. 17 , the prayer to Hera, must refer to a divine arrival.

38 From the context neither seems to be a god, but characters in Sappho's poetry do talk to gods, and apparently even chide Aphrodite (fr. 22.15-16). Quoted speech can be signaled by an introductory verb (fr. 1.16), but change of speaker also by no more than the change of person in a verb phrase (fr. 1.18, 25). The few letters admit many different supplements, and can be accommodated to different suppositions (I discuss this further, below).

39 See further Pirenne-Delforge and Pironti (2014).

40 I am grateful to Dirk Obbink for pointing out to me that the comments on the definite article in Lobel (1925), cited in the app. crit. in this volume for line 21 of this fragment, also apply in line 12: in this case, Lobel's observation that a noun with a specific reference 
be made in the future: the full cult prayer enjoined is not in this song. Yet, as in Alcaeus 129, the reference to a cult prayer that takes place at a different time (in that case, the past) somehow comes to be the prayer of the song itself; although this song is not a prayer, it seems to perform one indirectly.

But what is Hera being asked to do? Normally, with $\lambda$ i $\sigma \sigma o \mu \alpha$ one calls on a god, not a third party, to do or not do something, as in fr. 1. We could understand a missing imperative, 'grant,' such as we do find in the prayer to the Nereids,

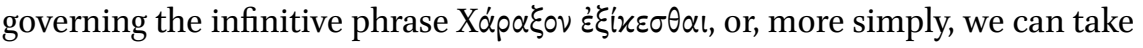
the infinitive phrase following $\lambda i \sigma \sigma \varepsilon \sigma \theta \alpha \mathrm{l}$ as an object (dynamic) infinitive with X'́p $\alpha$ Gov as subject, taking the form of indirect discourse: someone is to pray to Hera that Charaxos return, a third-person imperative, or that Charaxos may return, an optative of wish. However we take it, without an expressed request for action on her part, Hera seems remote; at this stage of the poem, it is the ritual, not the god, that is emphasized, just as in Sappho fr. 17 and Alcaeus fr. 129-at least as long as the immediate goal is safe return. And since we have the rest of the song, we know for certain that Hera disappears entirely at this point. Her role is subordinated in a capping gnomic statement and generalization that uses the contrast between divine and human spheres of knowledge and power (cited briefly just before the injunction to pray) to place the achievement of more than safety outside the scope of immediate prayer.

The shift away from the request that is proper to humans to the assertion that humans must acknowledge their dependence on divine favor-expressed as the sudden clearing of a storm - is marked by a shift to gods in the plural, as well as by the end of the string of infinitives. Then the poem takes a new turn; the capping gnome is really a transitional gnome. Now the song emphasizes, optimistically, the full and continuing extent of divine power. In the fifth stanza, the gods are particularized in the single person of Zeus - here identified as the king of Olympus - who takes over the action from Hera. If he wishes, he can bring about not just safety but extraordinary good fortune. Here, however, the problem of agency is raised explicitly. Zeus, as I noted earlier, sends other gods when he acts. His agent here is described as a daimon, sent as a helper, $\varepsilon \pi \dot{\alpha} p \omega \gamma \gamma \mathrm{v}$

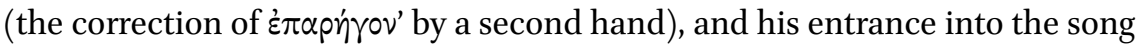

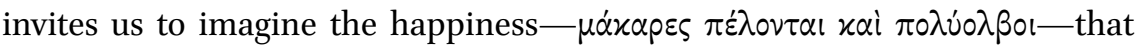

modified by a predicate adjective always has the article (p. xcii). Its absence therefore marks $\nu \hat{\alpha} \alpha$ as nonspecific. Pointing to the relative rarity of $\dot{\alpha} \rho \tau \varepsilon \mu \eta \dot{s}$, René Nünlist (2014) 13 notes the typological similarity of the prayer here to Odysseus' prayer for his own return, Od. 13.42-43, where the word also occurs. 
lies beyond a safe return. The address to Hera in a ritual setting, followed by a mention of Zeus, taken with its two close parallels, Sappho fr. 17, a prayer to Hera that includes Zeus and Dionysus, and Alcaeus fr. 129, a prayer to the Lesbian trinity, strongly suggests that the helper god involved would be

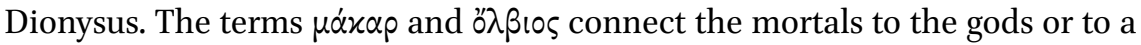
state beyond ordinary human happiness (cf. Sappho fr. 44A.8, Pindar fr. 137).41 Thus the transitional gnome of the god's control of human fortune gives way, in the next-to-last stanza, to a new and higher crescendo, a vivid vision of the divine blessedness that Dionysus can bring in the wake of a successful journey. ${ }^{42}$

At the most literal level it would be appropriate for the traveller to return with a full ship and be rich. No instances of $\mu \dot{\alpha} x \alpha \rho$ or ö $\lambda \beta$ 1o in Sappho or Alcaeus indicate that they used these words in that sense. And there is little reason to think that wealth itself is a major problem. ${ }^{43}$ All the readable instances of $\mu \alpha \dot{\alpha} \alpha a p$ in Voigt's index, starting with the vocative in Sappho fr. 1, the prayer to Aphrodite, describe, or appear to describe, the gods. There are only two

41 The words are discussed further by Bierl, ch. 14, this volume. In Pindar, Pyth. 10.1-2, $0 \lambda \beta^{i} \alpha$ $\Lambda \alpha x \varepsilon \delta \alpha i \mu \omega \nu$ and $\mu \dot{\alpha} \alpha \alpha i \rho \alpha \Theta \varepsilon \sigma \sigma \alpha \lambda i \alpha$ are celebrated for the connection their rulers have with Heracles.

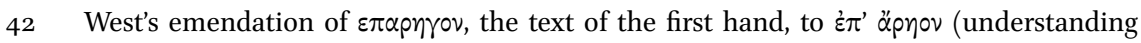
$\delta \alpha$ inov' to mean 'fortune'), is unnecessary. The basic idea in that reading-that those whom Zeus turns to better fortune become fortunate-risks banality, at best putting emphasis on the caprice of the gods, a topic already covered in the previous stanza. The text as written puts the emphasis on the hope that divine intervention take a specific form in the appearance of a third divinity who brings his characteristic joys. (I have not

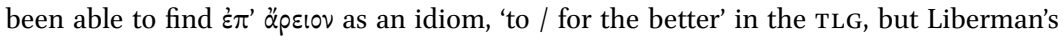
modification ([2014] 4), ג̇pท́ov( $\alpha$ ) solves that problem without changing West's meaning.) For a discussion and justification of the papyrus reading, see Obbink (2014b) 44 and Obbink (2015b) 6 with nn. 21-25 (including further acknowledgements to A. Henrichs and R. Schlesier). The syntax of the clause has caused much comment; I address it below.

43 Actual financial ruin is not likely to be contemplated in these poems. Even Herodotus reports only that the extent of Charaxos' extravagance was worthy of mockery. (For bankruptcy we have to go to Ovid.) The evidence for archaic economies is mixed, and difficult to interpret, but it seems that trade in the early sixth century was still no more than a marginal activity for the elite in a mostly agricultural economy, not a means of supporting socially well-placed families. The economic significance of their travels more probably involved the extra profits and status of selling and acquiring luxury goods. That does not, of course, mean that shifts in standing within the elite were unimportant to the participants. See Cartledge (1983); Foxhall (1998); Reed (2003) and Raaflaub, this volume. Liberman (2014) 5 compares the worries expressed in the Charaxos poem with the concern about a headband from Sardis in Sappho fr. 98 . 
readable instances of o $\lambda \beta$ ııร. One, in Alcaeus (fr. 42.14), describes Achillesobviously not to mark his wealth, but perhaps his heroic status. The other, in Sappho, describes a happy bridegroom (fr. 112.1). ${ }^{44} \pi 0 \lambda \dot{0} 0 \lambda \beta 0 \varsigma$ occurs only once in the previously known Lesbian poems, to describe Aphrodite (Sappho fr. 133.2); I assume that the adjective is used actively in that instance, passively in this line to indicate the giver and recipient of a happiness relevant to Aphrodite. However, it is hard not to infer wealth as an aspect of the meaning here, since it is common from Homer on (and we shall see that there are grounds for thinking that language may be used atypically in this poem). The world of Dionysian (and perhaps material) blessedness seems to merge with the gifts and status conferred by Aphrodite (the man enjoying the company of the woman in Sappho fr. 31, groom or not, is 'equal to the gods'). A turn toward Aphrodite would be consistent with fr. 5 and 15 .

In the last stanza, with a prominently fronted pronoun, separated from its clause, the song returns to the particular circumstances of the moment, a concern about Larichos. ${ }^{45}$ This is also where we find the turn to a public or civic sphere. The key word here for both turns is ö $v \eta p$. As noted in Obbink (2014b) 35 , it is rare in Sappho and refers to a groom or husband figure (fr. 16.7, 31.1; the 'workmen' of Sappho fr. 111.3 are contrast figures for the Ares-like 'man' of line 7). It is also a status term: Alcaeus uses it frequently to refer to any member of the sympotic society. The basic notion of line $22(18)$ is that he should become a husband and take his place as a full member of his social class; $\delta \eta \dot{\eta} \pi 0 \tau \varepsilon$ indicates that this would bring about an end to one episode, just as the safe arrival does.

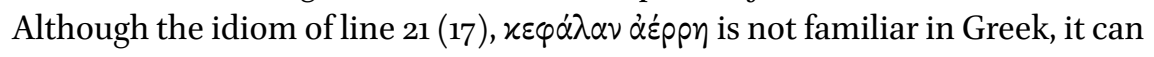
be understood in this light. Upon getting married he has to behave according to the ideals of the elite. The notion of holding up one's head has the connotation of manly, combative behavior. It is a boxer's stance, and a noble one. ${ }^{46}$ There

44 Nagy (2007a) $3^{1-36}$ proposes that Achilles is the ideal bridegroom in Lesbian song.

45 After a digression (in this case about divine action) we expect a return to the specific here and now. Such a return is emphatic, and in Sappho (and everywhere else, I think) typically

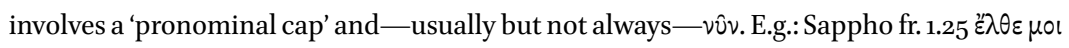
xai vôv. When the scene at hand is not temporally separated from the previous section, $\nu \hat{v} v$ can be used but it is not needed; cf. Sappho fr. 2.13, हैv $\theta \alpha$ $\delta \dot{\eta} \sigma \dot{v}, \ldots$

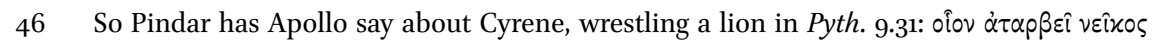

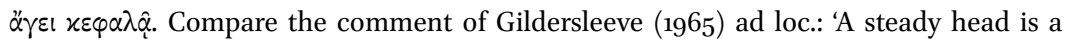
compliment as well as $\dot{\alpha} \tau \alpha \beta \beta \varepsilon \hat{\imath} \varkappa \alpha \rho \delta \dot{\alpha} \alpha$, which Schneidewin reads. Note the serenity of the heads of the combatants in Greek plastic art'. The use here corresponds to a call to military

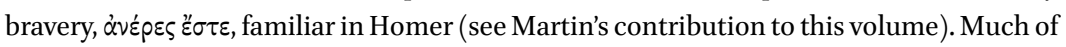
the immediate commentary on this poem interpreted the if-clause to mean that Larichos 
remains a Dionysian element, in the notions both of the symposium itself and in the use of boxing as erotic language in a sympotic setting (Obbink [2015 b] 8, 14 n. 34-35), and this would not be inconsistent with the hint of a Bacchic festival in the Nereid poem, or in other apparent conflations of Dionysus and

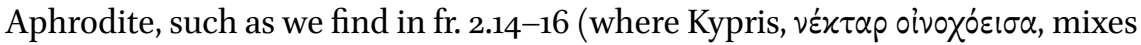
nectar, like wine, in golden cups). In the last line an optative, as in the Danaë fragment, the Nereid prayer, and possibly fr. 15 (but in the apodosis of a mixed condition rather than as a wish), underlines the change in emphasis from the safe return to the happiness that will follow.

\section{The Type and the Performance}

The pattern of a prayer for safety-one which does not begin with an elaborate invocation, in which the occasion and the accompanying ritual occupy the prime rhetorical focus, and in which cult, helpers, and the public good are all mentioned - can be seen outside of Lesbian lyric. In Pindar's Ninth Paean, for example, there is what looks like an invocation of Aktis, the ray of the sun, and, in a genealogical expansion, the mother of eyesight; further on in the stanza Aktis is addressed as Potnia. However, as the question in line 1 of the Paian shows, this is less a prayer to Mother Aktis, as if she were a deity, than a dramatic description of the eclipse which is the occasion of the poem. The remainder of the triad emphasizes a list of the possible disasters this portent might be foretelling, and not until the strophe of the second triad do we appear to get around to a prayer to an effective god, Apollo: these lines are the start of an extremely elaborate invocation. We assume there will be a prayer for Apollo's protection. ${ }^{47}$ The Ninth Paean appears to be closely connected with a cult ritual, a performance at the temple of Apollo Ismenios near Thebes, with special attention to the local hero Teneros and to the public sphere.

is immature, and looks down at his feet a lot, but we have no reason to suppose that he has not acted in a manner appropriate to a not-yet-married member of society, nor do any parallels suggest 'raise his head' as a metaphorical expression to indicate maturity. For Horatian uses of the idiom to suggest eminence, see Obbink (2015a) 4, with references to the commentary of Nisbet and Hubbard and contributions of Thomas Nelson. The implications of his social status are further discussed by Obbink, ch. 9, this volume. The image of an adult man hanging his head in remorse appears in Alc. fr. 358 , but no context opposes the one idea to the other.

Rutherford (2001) 193 suggests that there may have been a prayer in a (lost) paeanic refrain. In a hymnic structure, the narrative myth that elaborates the invocation may have been in turn followed by a prayer. 
More significantly for our purposes, Horace uses this form in Carmina 1.2. ${ }^{48}$ The prominence he gives the prayer as his first foray in Sapphic stanzas suggests a recognition of the pattern as a Lesbian type. The poem is rich in Horatian variation and in embellishment from other sources, but the sequence is clear. He begins with an extended description of disasters, which turn out to be standins for civil war (lines 1-24). He than makes reference to cult prayer to a goddess who protects households, with Vesta taking the place of Sappho's Hera $\left(25^{-}\right.$ 28); then the failure of such prayer motivates a shift, in the eighth stanza, to Jupiter as the god to receive the prayer (no motivation for appealing to Zeus was necessary in the Lesbian conception of a trinity). Horace does not ask Jupiter to do something himself, but to send a helper god (29-30), who, after a long priamel, turns out to be Mercury, standing in for Octavian (30-44). After finding this solution to the current evil, the poem looks ahead to hoped-for prosperity and further triumphs $\left(45^{-53}\right)$. With its emphasis on vengeance as the ultimate civic good-a form of ultor occurs three times $(18,44,51)$ - the poem looks to Alcaeus rather than Sappho, who caps her prayers with an emphasis on marriage.

Pindar's Paean performs a kind of fiction. By the time the song is written, the chorus trained, and the assembly gathered, it should have become fairly clear that the Sun had not left his accustomed track, even if the audience could not be certain that the end of the world was not near. No doubt there had been a recent eclipse, but the attention to Apollo and Teneros suggests something more regular, and less of an emergency. So too Horace Carmina.1.2 reflects the anxiety that had preceded the Battle of Actium, but its hopes for the future belong to later expectations that followed Octavian's success. ${ }^{49}$ Likewise, in the Lesbian poems, the extended emphasis on what is desired after the present danger ceases suggests that the opening scene is a reenactment, a presentation of a past anxiety as dark foil to the present hopes.

In the case of Sappho's poems, we can ask whether the numerous poems about a returning traveller belong to an actual historical incident in the life of a particular sister named Sappho who is forever obsessed with her older brother's behavior and bemoaning the distress he causes her, or whether they represent the poems of a society whose households, formed by marriage, were dependent for their social and economic status on leading aristocrats who frequently

48 The similarity of Horace's poem and Pindar's paean has been discussed by Syndikus (2001) 41 (following Cairns [1971]). In general, for the possibility of a direct link (not just a common heritage) from Lesbian lyric to Pindar see Trümpy (2004).

49 For a discussion of the dating see Nisbet and Hubbard (1970) 17-18, and Syndikus (2001) $38-40$. 
undertook the dangers of going to sea, and which developed, in consequence, regular rituals to reenact the uncertainty and celebrate the joy of their safe return. In such a case, the 'brother' figures would be types, not actual persons. ${ }^{50}$ If Herodotus' insertion of Charaxos into the tradition of stories about Rhodopis and other prostitutes has a basis in Sappho's poetry (something which the texts we have do not support, but which, experience shows, they can be made to accommodate), this too would be a typical feature of dangers faced by travellers (cf. Alcaeus fr. 117b.26-31).51

The notion of a ritual performance context for these poems leaves two questions unanswered: why, if they have a common formal base, are they so different, and what is the conception of Kypris that figures in them? For answers

50 For stock stories in the early archaic tradition, see West (1974) 1-39. There have been various suggestions about the possible significance of the names in Sappho's poems as 'speaking names,' supporting various theories of performance or ritual function. Rudolf Wachter (2014) notes that the names Charaxos and Larichos are hypocoristics; he derives the former from the compound $\chi \alpha \rho \alpha \xi i-\pi o v \tau o s$ 'ploughing the sea'; and attaches the latter

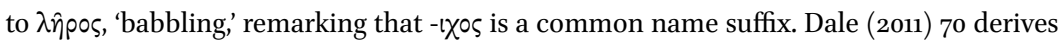

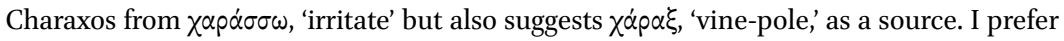
the last, because it would establish a connection with Dionysus and wine-growing (as well as allow for the word-plays on $\chi \alpha \rho \alpha$ ). Such a connection would be maintained in the name of Larichos, whom Hellenistic commentaries (gathered in Sappho test. 203) explicitly connect to wine, by understanding it from $\lambda$ após, 'sweet', used by Homer of wine. It would represent the joy of the symposium or festival. (See also Bierl, ch. 14, this volume.) With the feminine of the same suffix, Doricha represents, simply, "gifts" - an appropriate name for a woman in any case, and in particular for the stock character of the bride, since brides and marriages are widely associated with gifts (so Sappho fr. 44). G. Nagy, this volume, connects "Sappho" to a root for "sister," reinforcing the family relationships in the poems. I prefer to derive "Sappho / Psappho" from the root that also furnishes $\psi \dot{\alpha} \mu \mu \circ \varsigma$ and Lat. sab-lum (see Chantraine [1999] s.v. $\psi \dot{\alpha} \mu \mu \circ \varsigma$ ), and, indirectly, the Nereid Psamatheia (Pindar, Nem. 5.13), as an indication of the importance of the sea to the family of wine-producers, whether stock or real. But proposals vary widely. Schlesier (2013) argues that all the female names are nicknames for prostitutes. The evidence of the new discovery does not settle the question of whether 'Charaxos' instantiates the absent figure in one poem, or should be understood as the stock name for all brothers at sea.

$5^{1} \quad$ Evidence for the role of prostitution in early trade is gathered in Aloni (1983). His discussion remains valuable even without his theory of conflict between landed aristocrats and traders. A key text in this discussion is Alc. fr. $117 \mathrm{~b}$ (from P.Oxy. 1788). On the question of whether the fragment is rightly assigned to Alcaeus, see the review of evidence and arguments in Liberman (1999) LXXXVII-XCI. I do not find his doubts persuasive, but whoever composed the song must be reflecting available Lesbian points of view. 
to these questions, it will be helpful to consider another group of poems, which center on love and are radically dissimilar to one another.

\section{Love Songs}

We have five poems explicitly about the power of love. The manuscripts of the rhetorical tradition have preserved two extended sequences about love (Sappho fr. 1, apparently complete, and fr. 31), to which we can add an ostracon that appears to be a school text (fr. 2). Papyri yielded fr. 16, and now new additions to that poem and the start of a new one (the new prayer to Kypris). These poems display the power of Aphrodite and of erotic desire, and the inability of humans, unaided, to transcend or control that power. They are illustrations and avowals of human dependence on the gods. They all describe the praxeis of Aphrodite. But their unity stops there. Rather, we can observe in them very different types of rhetoric, and differences in tone-different voices.

\section{Sappho frs. 1, 2, and 31}

The opening prayer to Aphrodite, Sappho fr. 1, exemplifies the form of cult prayer I mentioned above. It also illustrates how the form is capable of literary development. There is an extended invocation. The central part, the hypomnêsis, deftly fits the god's own reminder of her help to Sappho into Sappho's own recollection of the god's responsiveness. The inset section closely adheres to the template of scenes of epiphany, such as Apollo's visit to the wounded Hector in Iliad 15.236-251: He arrives like a bird, chides his favorite, reminds him of his past protection, and encourages him to go on. Sappho ends the poem with a prayer to Aphrodite to come and be her military ally. The tone of the poem is notoriously hard to pin down: a desperate voice of the petitioner in pain is followed by the voice of a god both laughing and consoling, and in the end the petitioner seems to show new confidence and determination.

Fragment 2 is a cletic prayer summoning Aphrodite to a sacred grove; it contains an extended ecphrasis of a natural scene, something very rare in early Greek literature; the tone of lulling enchantment details the sounds, scents, and sights of the precinct. ${ }^{52}$ It illustrates how Sappho uses style and sentence structure for expressive effect. In comparison to other poems it abounds in

$5^{2}$ There are hints of ecphrasis in Alc. fr. 115 - one reason that P.Oxy. 1788 is sometimes ascribed to Sappho-and Alc. fr. 45, the hymn to Hebros, shows that descriptions of nature are not foreign to Lesbian poetry. 
sonorous long words and phrases - particularly three sonorous pentasyllabic

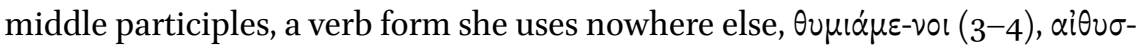
$\sigma o \mu \varepsilon v \omega \nu \nu(7),\langle 0\rangle \mu\langle\mu \varepsilon\rangle \mu \varepsilon i \chi \chi \mu \varepsilon v \circ \nu$ (15) —and minimizes the separation of lines by frequent run-over phrases and enjambment. ${ }^{53}$ Uniquely among this group of poems, Aphrodite's presence is taken to be wholly beneficent.

The tone of fragment 31, the famous pathography, could not be more different. After a traditional comparison motif in which the speaker contrasts her own lack of self-control in front of the beloved with the composure of a hypothetical man 'equal to the gods' (whether in strength or happiness), it lists the disabling symptoms of love. No word for 'love' or 'desire' is actually used-her intensity and lack of distance from her suffering is reinforced by the avoidance of abstract terms-but $x \alpha p \delta i \alpha \nu . . . \dot{\varepsilon} \pi \tau \tau^{\prime} \alpha I \sigma \varepsilon v$ is a descriptive paraphrase that leaves no doubt (cf. Alcaeus fr. 283). A symptom list also occurs in Sappho's poem on old age (fr. 58 , the Tithonus poem) and in Anacreon's (fr. 395), but by its length, careful patterning, and application to love here, it emphasizes a tone of exceptional distress. In what appear to be a few words of a following stanza'all things can be borne' - there are indications that after the mention of death the persona of this song would have stepped back and concluded by drawing attention to the limits of the human condition.

\section{Sappho, fr. 16}

Fragment 16 famously illustrates the priamel; Sappho ostentatiously demonstrates the application of a universal principle to explain her own experience. After a list of foils there is a pronominal cap marking a general or gnomic cap: 'I say that (the general rule is that) anyone finds most beautiful whatever (s)he loves. This is illustrated by a mythic exemplum chosen because it also provides an a fortiori argument - the person most universally regarded as beautiful still found, because of love, someone she thought most beautiful. We know this from the action of the story: her love led her to violate the most universal norms of good behavior by ignoring her parents, child, and excellent husband. The myth ends in a break-off passage (about which we now have more knowledge), and the priamel concludes with the expected 'concrete' cap, marked by vôv, the repeated pronoun and a proper name. At this point the singer returns to the here-and-now of the circumstances which are the (possible or fictive) occasion. The poem's structural formality is the guide to its distinctive tone. Here,

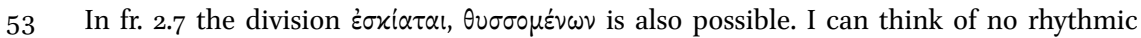
rationale for Sappho's avoidance of the middle participle; perhaps it simply represented an inefficient ratio of sound and sense. There may be a partial exception in Sappho fr. 5.19, where the root aorist, $] \theta \varepsilon \mu\left[\varepsilon^{\varepsilon} v\right] \alpha$, is a more compact form. 
especially, readings that reject the presence of the gnomic or universal in this poem because of an a priori conception of the personal character of Sappho's style, mishear the voice. ${ }^{54}$

Before the new discoveries it was possible to speculate that the climax to the myth appeared in the continuation of the action into the fourth stanza (cf. the end of the myth in the Tithonus poem, Sappho fr. 58.12, final line in the Cologne papyrus). In that case xov́ $\varphi \omega \varsigma$ would have been part of a narrative describing Helen entering Troy or Aphrodite's appearance to Helen. Another hypothesis was that the myth ended with a generalization on women or on the power of

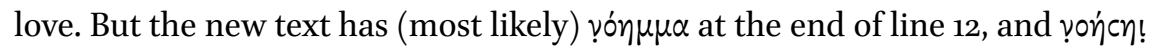
at the end of line 13:

$$
\begin{aligned}
& \text {... } \quad \dot{\alpha} \lambda \lambda \dot{\alpha} \pi \alpha \rho \alpha \gamma^{\prime} \alpha \gamma^{\prime} \alpha v^{\prime} \tau \alpha \nu \\
& 12 \\
& \text {.] }[\ldots . . .] \operatorname{cov}[
\end{aligned}
$$

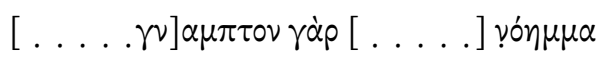

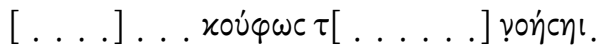

The focus, therefore, is on mental activity. The mind is not likely to be Sappho's (as suggested in Burris and Fish [2014], see below), because-in fulfillment of the formal structure - she should not reappear until, in line 15, she explicitly applies the exemplum to herself and the present situation with a typical capping statement. It is not likely to be a generalization based on Helen's flexible, $\gamma v] \alpha \dot{\alpha} \pi \tau \circ v$, mind, since she is not the formal topic of the myth. The myth illustrates the power of love or desire, and within the constraints of the remaining space, only a generalization about that power looks possible. Such a generalization would bring the myth to a close and prepare the transition to the final cap, with its specification of the preference of the persona cantans. This is what we would expect from the exacting strictness of form in this ode, both before and after this point. Break-offs from the narrative signal a climax and an end, and they typically contain a general statement about

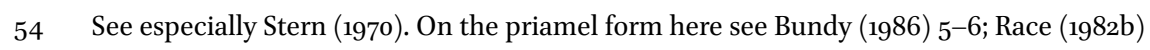
7-17, 63-64. Page (1959) 55-57 cites clarifying parallels, but it is misleading to say 'the audience will be alert to catch the name of the favorite. Sappho keeps them in suspense' (58). The audience knows the form and will be equally alert to hear an exemplum of the principle. There is a good overview, with bibliography, of all the complexities of the structure of this poem in Pfeijffer (2000), although I think his conclusions depend too much on searching for analogies between characters inside and outside the myth and too little on the formal demonstration of a principle of action. 
the power of the gods and the ease with which they exert it - what is sometimes called the thauma motif (Bundy [1986] 2-3; see also Race [1980]). The god, in one form or another, is Aphrodite. The question is whether the vón $\mu \mu \alpha$ belongs to Aphrodite or her victim - whether Aphrodite has, [ $\left.{ }^{\prime} \chi \varepsilon \varepsilon\right]$, an unbend-

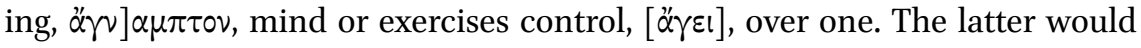
require some kind of concessive: she controls even an unbending mind. ${ }^{55}$ Either thought would generalize from the end of line 11 in the previous stanza, where $\pi \alpha \rho \alpha \gamma \alpha \gamma^{\prime} \alpha v^{\prime} \tau \alpha \nu$ (Helen), in the narrative, indicates the force of eros. At the end of the adonean ] $\sigma \alpha \nu$ looks like a feminine accusative modifying Helen. Since the point of the story is that she had no control over whom she found most beautiful, the adonean should indicate that her error was forced on her: $x \circ u$ ix $\varepsilon \theta \varepsilon \lambda^{\prime} \circ \omega_{\sigma} \alpha \nu$ gives the idea and accommodates the accent in the previously published papyrus. ${ }^{56}$ The opening word of the fourth stanza would supply the subject: Kú $\pi$ p l looks most likely for the space. ${ }^{57}$ I prefer next a reading that focuses solely on the gods' power to fulfill their (to us incomprehensible) intentions; for example:

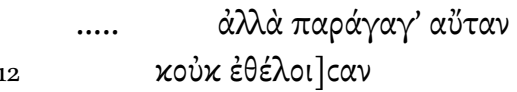

This is West's preferred understanding ([2014] 2-3); he illustrates the possibility by putting the concessive adverb in the gap in line 13 and the verb in the next line, with a result clause

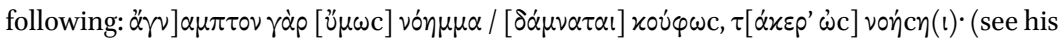
comment on the verb choice). I am not sure of any result clauses with $\dot{\omega} \varsigma$ + subjunctive in Sappho.

$5^{6}$ See Obbink's app. crit., ch. 1, this volume. His supplement $x$ o $x \dot{\varepsilon} \theta$ - is a variation of M. Tempesta's suggestion, o $0 \dot{\delta} \dot{\varepsilon} \theta$ - (cited in Burris, Fish, and Obbink [2014] 17 ad loc.). The change accounts for the position of the "warning" grave accent as the second letter of the

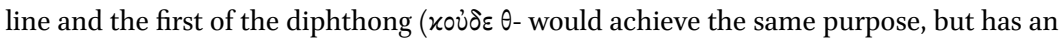
otiose conjunction).

57 I was wrong to suggest (Burris and Fish [2014] 16 ad loc.) $x \dot{\alpha} \lambda \lambda_{0}$ s as a possible subject, since that undoes the logic; if it said that she loved him, therefore found him beautiful, and his beauty then led her astray, the poem would be about the effect of beauty and only indirectly about love, and the next sentence would then have to be about the power of beauty. The scribe's confusion of 'him' and 'her' at the end of line 11 would arise from the common expectation that Kypris led Paris to Helen, not the other way around. (If $\gamma \nu \alpha \dot{\mu} \mu \pi \tau \nu$ is positive, it leaves a three-syllable gap, for which I suggested ' $\mu \varepsilon \rho$ p ). The position of ráp all but guarantees that the first word concludes the previous sentence; no one has suggested a suitable four- or five-syllable word that ends in ] $\alpha \mu \pi \tau o v$ to begin the sentence. Sappho is strict about not postponing róp and she does not separate xai ráp. And if the subject were in the adonean, it would be hard to find a word suitable for the run-over. 


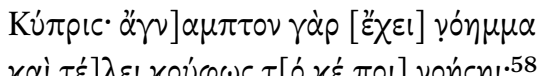

But Kypris led her astray, / even though she did not even wish it; / for (Kypris) has an unyielding intention / and accomplishes lightly whatever she intends.

A gap at the start of line 15 leaves open the question of what or who reminds Sappho of the absent Anactoria. The pronoun 'she' would have to mean Aphrodite ( $\ddot{\alpha}$ attributed to Fraccaroli by Voigt). This is possible because her ability to affect the mind has just been reported. It would make the parallel between the persona cantans and Helen closer, but it would also imply a parallel between Anactoria and Paris, which is particularly distracting at the point when the subtext suggests that the "I" of the poem thinks that Anactoria shares Helen's beauty. I suggest instead that it is the whole thought - the principle of the gnome and the example-that reminds her. This would sustain the poem's illusion of spontaneity ('Unlike others, I believe that ..., and this makes me think of my desire for Anactoria'). So of all the possibilities, $\tau$, the word she uses for a similar back reference to a whole situation in fr. 31.5 , is most appropriate here. Because the re-introduction of herself as the topic calls for the emphatic

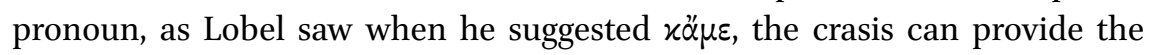
necessary long vowel: 59

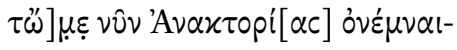 \\ 16

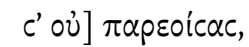

The crasis $0+\varepsilon>\omega$ is known (Hamm [1958] $39 \S 80 . \mathrm{g})$ ) but not common. This is what led Burris and Fish (2014) to suspect that the annotation $\tau \omega \mu$ v, with an attribution to Nicanor or Nicander, in the left margin of Sappho fr. 17 in PSI 123 should be thought of as being in the right margin of the preceding column, lost in that papyrus, at line 14 of this, the preceding poem, and so supply a possessor for von $\mu \mu \alpha$. In that case, the lost text in PSI 123 would have had the

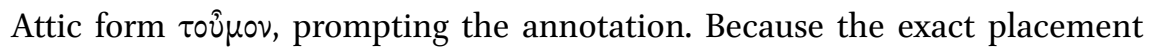

$5^{8} \pi \circ \mathrm{l}(=$ Attic $\pi \circ \nu)$ corrects an error in my earlier suggestion of $\chi \varepsilon \dot{\varepsilon} \pi \omega$, reported in Burris,

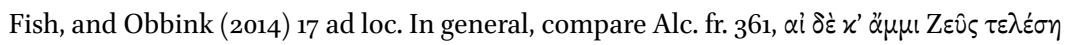
vó $\mu \alpha$, 'if Zeus fulfills our plan' (Campbell), or 'fulfills for us his plan'. For the relative $+\chi \varepsilon$ and the subjunctive instead of ö $\tau \iota$ here, compare Alc. fr. 358.6-7. using it. 
of the annotation in relation to the text is uncertain, and because the return from the myth to the hic et nunc in $\mu \varepsilon$ vov strongly suggests that there should be no earlier self-reference (or even precludes one), most commentators have put aside their suggestion. My proposed supplement in line 15 provides an alternative explanation for the annotation: the annotator mistook the letter sequence $\tau \omega \mu \varepsilon v$ and meant to correct it with a variant that he knew occurred in Sappho. If Burris and Fish are correct in pointing to a monograph on crasis by Nicanor, it could have provided the evidence for the alternative reading but without making clear exactly where it belonged. ${ }^{60}$

The persona of the singer here has persevered with a cool rhetoric, displacing any strong emotion to the mythical past. With the mention of Anactoria, the priamel is formally complete. The assumed mask appears to drop slightly in the

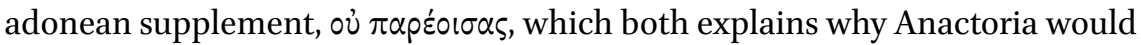
be on her mind and adds a suggestion of longing. But the expression of emotion remains restrained, with a softened wish to confirm her choice in the optative in line $17, \tau \hat{\alpha}] \varsigma\langle\varkappa\rangle \varepsilon \beta 0 \lambda \lambda \circ i \mu \alpha \nu$, and, in the remainder of the stanza, a rhetorically self-conscious application of the original foils, supposedly discarded, to the qualities of Anactoria's appearance.

It is not clear whether the poem continued after this stanza. On the one hand the formal structure is complete; on the other, there has so far been no statement that the persona of the singer accepts her loss or her dependence on divine power, such as seems to appear in the all-but-lost last stanza of Sappho fr. 31 and which is implicit in the prayer forms of Sappho fr. 1 and fr. 2. At line 20 we are left with an open-ended sense of her dissatisfaction. It now seems all but certain that there were enough stanzas for another poem between this one and Sappho fr. 17. The published text tentatively starts the next poem, fr. 16a with line 21, giving fr. 16 itself five stanzas, but there is potentially enough room for a complete new poem to start with fr. 16a.25, leaving a possible sixth stanza for

6o According to McNamee (2007) 355 with $35^{6} \mathrm{n}$. 23, the annotation is in the form associated with variants, not a confirmation of a reading (she is following Turner's system). As Burris and Fish show, the range of lines to which the annotation could apply is not great; so it is wishful thinking to ignore it completely. By my hypothesis the annotator would have thought that a second von $\mu \mu \alpha$ should be mentally supplied from above, which would yield the minimally acceptable sense, 'mine (sc. my thought) now takes note of Anactoria'. He would not have noticed either that he was using one nu twice, or that an additional nu would make the line unmetrical. There is another, unmetrical miscorrection in the same papyrus, placed interlineally in fr. 17 line 3 (see app. crit. in Voigt; a photograph is available at http://www.psi-online.it/documents/psi;2;123). I am grateful for additional correspondence on my speculations from Professors Fish and Obbink. 
Sappho fr. 16 (The text of new finds confirms but does not add to what was in the already published Oxyrhynchus fragments for lines 21-22; the end of line 23 is new; there is no trace of the adonean.):

21

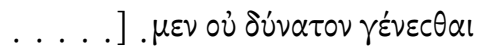

$$
\begin{aligned}
& \text {. . . . . . . } v \dot{\alpha} \nu \theta \rho \omega \pi[\text {. . . . . } \pi] \varepsilon \delta \delta^{\prime} \chi \eta \nu \delta^{\prime} \ddot{\alpha}^{\prime} \rho \alpha c \theta \alpha \iota
\end{aligned}
$$

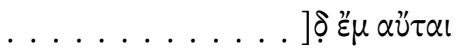

The potential optative wish of line 17 implies 'if I could'. The suppressed protasis is usually ignored in that idiom, but 'not be possible' in 21 could respond to the thought. The correlated structure suggests that something as a whole is not possible for humans, but one can pray to share in it (for the expression cf. Sappho fr. 63.5-6). Such a generalization could begin a poem as well as end one, but it seems less suitable to what we now know is the end of the next poem (Sappho fr. 16a.30-32):

$$
\begin{aligned}
& \text {... ő } \tau \tau i v \alpha c \gamma \alpha \dot{\rho}
\end{aligned}
$$

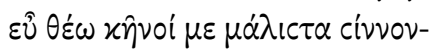

$$
\begin{aligned}
& 32 \\
& \tau^{\prime} \xi^{\prime} \xi \dot{\alpha} \delta \circ \alpha \eta^{\prime} \tau \omega
\end{aligned}
$$

for whomever / I treat well, they especially harm me / unexpectedly.

It seems to me harder to connect an introductory stanza (16a.21-24) on the limits of attainment to this final generalization on the inability to know one's friends (a theme of the limits of knowledge or the uncertainty of fate) than to connect an initial statement about desire $(16.1-4)$ to a generalization on the limits of obtaining what one wants. And as the end of fr. 16, a stanza on the recognition and acceptance of limited happiness would continue the tone of restraint without contradicting a possible underlying sense of regret. ${ }^{61}$

61 'One's whole sense of the poem would be affected by whether the narrator touched fairly briefly on her own experience at the close, and ended both neatly and wistfully at 20; or whether she moved to dwell on her own suffering at greater length, and to incorporate it into a further large context' (Hutchinson [2001] 167). The uncertainty about the last stanza mirrors the problem of Sappho fr. 31, in which line 16 closes a ring, but the poem does appear to continue with a generalization, and of Sappho fr. 58 - the newly expanded Tithonus poem - which is apparently complete at line 12 in one version, but continues with a four-line comment in the other (these three poems were discussed together by Lardinois [2009] 42-51; the new additions to fr. 16-16a confirm the relevance of his comparison). Although we now know that at most only one further stanza was 


\section{Sappho, Kypris Song}

No such emotional restraint characterizes the new prayer to Kypris. Although we have at best readable remnants of six lines, the tone is difficult to mistake. The anguish is similar to Sappho fr. 31 , but it is achieved very differently. Unlike the others, it does not appear to be constructed from a traditional rhetorical type. Elsewhere rhetorical questions are introduced as pretexts or hypotheticals in an argument (so Alc. 119.1, apparently), but I can find no other early examples of a purely exclamatory rhetorical question as an opening gambit:

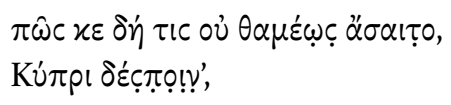

How can someone not again and again feel distress, / Kypris, my mistress,

Strained word order reflects the singing persona's emotional strain. Instead of the normal $\circ \ddot{v} x \varepsilon \delta \dot{\eta}$ the negative is moved forward, apparently to form a quasi-compound with $\theta \alpha \mu \varepsilon \dot{\varepsilon} \omega \varsigma$ and accentuate the anguish (Obbink [2014b] 46).

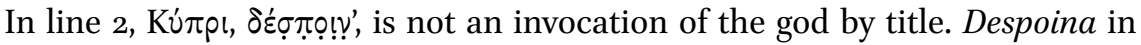
early Greek can readily be used of humans in authority - typically the Lady of the house. When used for gods it has a defining genitive, such as Anacreon

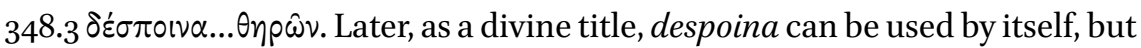

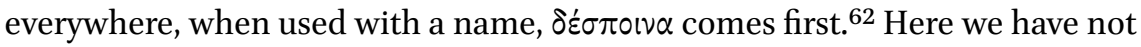
Lady Kypris, but something much more emphatic, such as 'Kypris, my queen'.

likely, various solutions previously suggested for fr. 16.21-22 and found in Voigt's app.

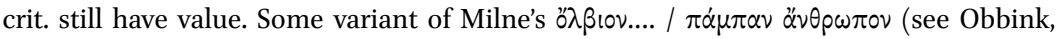
ch. 1, this volume), 'it is not possible for a mortal to be completely blessed' also has the advantage of fitting the alphabetical order as an incipit, and therefore allowing the question to remain unresolved. As a continuation, it would be extremely general, since there has been no indication of olbia as topic. Sitzler's $\alpha \lambda \lambda^{\prime} \alpha \ddot{\rho} \alpha \nu . . . . / \pi \alpha \hat{\imath} \sigma \alpha \nu$ suggests that there has been actual prayer- $\alpha \dot{\rho} \alpha$ is usually concrete. (Hutchinson finds the former too short, the latter too long.) The asyndeton, which Sitzler's supplement avoids, would not necessarily be a marker of a first line. No such rule should be imposed as an editorial requirement, since asyndeton can also occur at the start of a generalization within a poem. There may be something very similar at Sappho fr. 96.21 (where some scholars have wished to apply the rule) and there are numerous examples in Pindar (e.g. Pyth. 2.49).

62 For the use of the title, see Henrichs (1976). My observations on the word order are based on his thorough collection of instances. 
Note that here the use of generalizing indefinite pronouns does not disguise the actual particularity of the experience; $\tau \iota \varsigma$ and ö $\tau \tau \imath \nu \alpha$ make us guess at or imagine the particular individuals whom the persona cantans cannot bring herself to name, including (at least) herself.

The exact grammar and meaning of the second line is not clear, because we

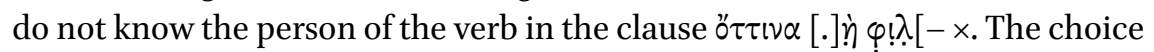
is between a second person indicative, $\varphi i \lambda[\eta \sigma \theta \alpha$, and a third person, indicative or optative, $\varphi^{i} \lambda\left[\eta \sigma \iota\right.$ or $\varphi \iota \lambda\left[\varepsilon^{\prime} \eta \eta\right.$. The choice of construction also influences the choice between $[\delta] \dot{\eta}$ and $[\mu] \dot{\eta}$. Neither construction is without problem. If second person, 'whomever you (do not?) love,' the indefinite relative specifies the class of an indefinite antecedent in the first line. But all other examples

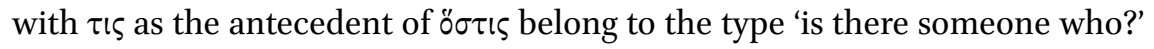
or 'there is no one who' (see Kühner and Gerth [1904] sect. 544(.3) anmerk. 7), and indeed one hardly expects an indefinite to define an indefinite: one of them is otiose. In the case of the third person - 'if (s)he loves someone'-we would have an example of what Smyth calls a parenthetical or appended general conditional relative clause ([1984] 579, sect. 2570), which uses the indicative. But in all examples I have found there is some noun in the sentence which can function as the antecedent, a hook from which the appended clause hangs (see also Kühner and Gerth [1904] sect. 558.6; another good, archaic example is Semonides fr. 7.69-70). So the construction would be noticeably loose. Given this choice, this second, loose construction seems to me preferable. It does not violate the inherent logic of the indefinite pronouns, and it conforms to the general style of the passage as an abrupt burst of thought. In that case, only $\delta \dot{\eta}$ makes sense as the particle. ${ }^{63}$ The clause describes the circumstances of the initial exclamation.

In the next line the optative $\theta \dot{\varepsilon} \lambda$ or establishes a construction parallel to the optative in the first line, resuming that construction after the grammatically parenthetical clause. A conjunction is needed, the space is slightly too wide for $x \alpha$ í, and a negative would continue the parallel, so $x \omega \nu$ seems to be the best choice. ${ }^{64}$ At the end of the line, an aorist infinitive, $\pi \dot{\alpha} \theta \eta \nu$ would require,

63 The repeated $\delta \dot{\eta}$ is not a problem; see Obbink (2014b) 47 ad loc. With the second person, $\mu$ ' would indicate that the suffering belongs to those whom Aphrodite does not love: presumably, she causes them to fall into a love that is not requited, as an expression of her displeasure. More generally, however, as in fr. 1 and fr. 2 , she is called on to create love, and it is her absence which is deplored. Aphrodite's favor brings a passion that can cause the experience of pain as well as of pleasure. (See also Benelli [2015] 10.) There is an extensive discussion of this stanza by Schlesier, this volume.

64 Benelli (2015) suggests a new clause with initial crasis of $x \alpha i$ + + i ('if') here; he also proposes 
for the next word, either an object beginning $x \alpha$ - or $\chi \alpha$-, or another infinitive. None of the choices for a noun give good sense. An infinitive would have to govern $\pi \dot{\alpha} \theta \eta v$ and the resulting expression 'wish to (...) to suffer' is likely to be unnecessarily awkward or redundant. It seems more likely that there is a noun here, governed by an infinitive at line-end, and also more likely that Sappho shares Pindar's form for the noun of the $\pi \alpha \theta$ - stem, $\pi \dot{\alpha} \theta \alpha$, than that she uses $\pi \dot{\alpha} \theta 0 \varsigma$, which is found in Attic in the fifth-century and later. Although one can 'suffer' evils or 'experience' goods with the same verb in Greek, the unmodified word normally means 'suffer,' and in Pindar the forms of $\pi \dot{\alpha} \theta \alpha$ usually refer to evils. In addition, the parallel of the optative phrase here with $\ddot{\alpha} \sigma \alpha \iota \tau$ in line 1 suggests that the paramount idea is 'suffering. The noun here could be, with a final nu, accusative singular or genitive plural (or, with a final sigma, accusative plural or genitive singular). West has suggested $x \alpha \lambda \nu$ in $\tau \varepsilon เ \nu$ with an accusative, but there is no parallel for anyone wishing to hide the experience of love in Sappho rather than speak to the beloved. The supplement $\chi \alpha \dot{ } \lambda[\alpha \sigma \sigma \alpha \iota$ with the genitive follows the pattern of Alcaeus, fr. 70 (see app. crit. in this volume), where Alcaeus urges his comrades to seek respite but with a view to future fighting and victory. ${ }^{65}$ This may be a military commonplace; in Homer, Iliad 19.221 Odysseus, arguing with Achilles, declares that xópos comes to fighting men (compare $\ddot{\alpha} \sigma \alpha i \tau 0$ ), and they must then have a respite in order to resume fighting again. For the full opening question, therefore, I follow the reading:

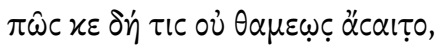

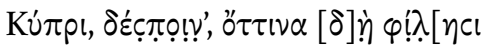

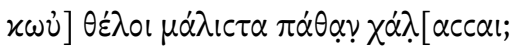

How would someone not be continually overwhelmed, Kypris, my queen, if (s)he indeed loves someone, and (how could someone) not most of all wish to get respite from sufferings?

the crasis $x i$ - in line 6. But notwithstanding the frequency of $x \alpha i$ $\varepsilon \grave{i}$ in Greek generally, Hamm ([1958] 38-39, sect. 80-81) records no instances of crasis of $\alpha(\iota)+\alpha \iota$ (and it is difficult to suppose that $x \alpha i$ and $x \alpha i$ would differ in pronunciation), no instances of crasis of any vowel with an initial iota, and no examples of elision of $x \alpha$ t that could not be interpreted as crasis with a following alpha.

65 So too Liberman (1999) ad loc.; the question of whether Alcaeus is using a subjunctive or future is not relevant here. 
Another unusual feature of the stanza is the syntax of the adonean. Because of the change to second person in line 4 , we can be fairly certain that the opening question ends at line 3: the adonean has to start a new sentence. This never happens elsewhere in Sappho. The adoneans either end, usually with a climax, the previous clause (as in the first stanza of fr. 1), or they form a prominent transition to its conclusion in the next stanza (as in the second stanza of fr. 1). ${ }^{66}$ Alcaeus begins a sentence in the adonean once, in fr. 42.12, but that may be the exception that demonstrates the rule; the sentence is closely connected in thought to the previous one:

$$
\begin{aligned}
& \varphi 1 \lambda{ }^{\prime}\left[\tau \alpha c \delta^{\prime} \ddot{c}^{\prime} \theta \alpha \lambda \varepsilon\right.
\end{aligned}
$$

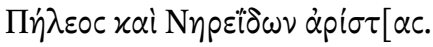

$$
\begin{aligned}
& 12 \\
& \text { ह̇c } \delta^{\prime} \text { Èvíavtov }
\end{aligned}
$$

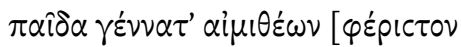

The love thrived / of Peleus and the most excellent of the Nereïds, / and in a year // she gave birth to a demigod'.

supplemented text from PAGE [1959]

The sentence that begins in line 4 connects the second person description

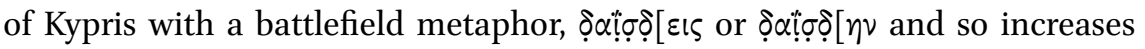
the intensity of the complaint. If the sentence is a new question, it would furnish a similar continuity of thought, and excuse the asyndeton. Although

66 A reading that ended a sentence in line 4 would provide a normal stanza structure. It

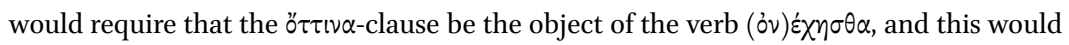
have the advantage of providing a clearer attachment of that clause to the sentence structure (See Benelli [2015]). However, there is no meaning for the verb that would provide an acceptable sense (see LSJ; ( $\partial v) \varepsilon \chi \eta \sigma \theta \alpha$ cannot be construed with an infinitive in line 3 , because an infinitive there would be dependent on $\theta \dot{\varepsilon} \lambda$ ○). Since the verb is indicative, it describes the goddess's action; the persona cantans is apparently addressing to Kypris, in the exclamatory question of line 1 , a complaint about her experience in love, either holding her responsible or looking to her for relief. Such a question would not readily lead to a description of how the goddess does or does not restrain or physically hold high (or metaphorically exalt) her or anyone else. Because of the implied complaint, it is tempting to look for a reading that brings the poem closer in sentiment to Horace, Carm.4.1, complaining to Aphrodite that whomever she loves who wishes to give up these activities, she goads instead (by litotes here, for 'does not restrain'). But precision of vocabulary, available syntax, and the absence of parallels within what we have of Sappho resist such a reading. 


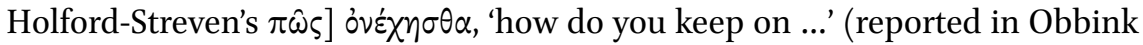
[2014b] 48 ad loc.), with the repetition of the poem's opening word is very attractive, the verb requires a supplementary participle, a form not possible at the end of line 5, never an infinitive. The printed version, $\pi \circ \hat{0}] \circ v$ है $\chi \eta \sigma \theta \alpha /$ $\nu \hat{\omega} v]$, (E.L. Bowie) 'what intention do you have', recreates an idiom also supplemented in Sappho fr. 96.2, but it lacks dramatic intensity and is dialectically

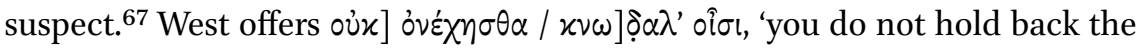
mordacious pests with which ...' $(2014,12)$ as part of a version which begins the main clause in line 3 . The sense is difficult, but the relative clause has the advantage of unambiguously placing the enclitic pronoun in second position. In other versions, the pronoun is second within a dependent infinitive clause. That placement is likely to be acceptable, but there are not enough instances for certainty. ${ }^{68}$ Hesitantly, nonetheless, I prefer a version with the infinitive that also adds a new word to the lexicon, $x \alpha \dot{\gamma} \gamma \times \alpha \lambda \circ$ s. The form would be related to $x \alpha \gamma \chi \alpha \lambda \alpha \omega \omega$, 'laugh in exultation, jeer,' just as the Aeolic thematic stem $\gamma \varepsilon \dot{z}$ os exists alongside of $\gamma \varepsilon \lambda \alpha \dot{\alpha} \omega$ (see Chantraine [1999], s.v.). There is also a later verb form $x^{\prime} \gamma \chi \alpha \lambda i \zeta \omega$, which would be a regular formation from the thematic stem. ${ }^{69}$ I would incorporate this, as a dative of manner (not means), in a progression from the exclamatory question to a normal exclamatory declarative sentence:

4

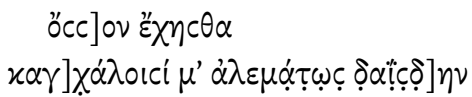

How much you are able,

in bursts of laughter, to pierce me heedlessly ...

Here $x \alpha \gamma \chi \alpha \dot{\lambda} \lambda \circ{ }^{\prime} \sigma$ expresses pejoratively what $\mu \varepsilon เ \delta 1 \alpha i \sigma \alpha l \sigma \alpha$ does positively in fr. 1.14, just as $\alpha \lambda \varepsilon \dot{\varepsilon} \mu \alpha \tau \omega \varsigma$, emphasizing the gods' disregard for human conse-

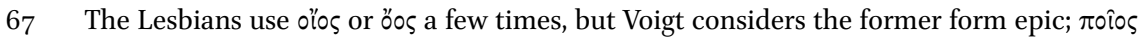
does not occur. On $v \omega \hat{\nu}$, see Hamm (1958) 29-30, sect. 58.2 .

68 See the separate note on fr. 17.4 in this volume. Although Taylor (1990) 65 finds it only 'marginally' possible in Homer for an enclitic in an embedded non-finite clause to take

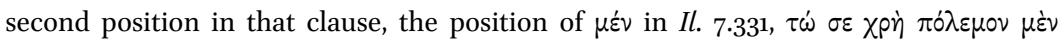

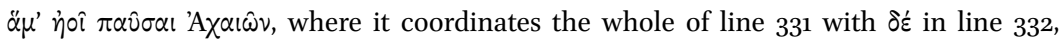
shows that it is certainly possible. (Sappho fr. 94.5 and 1.17 show that it is not necessary).

69 Hesychius (see LSJ Suppl.) reports the noun as a Sicilian word for a (bolt-?) ring or hole (xpixos) on a door. Perhaps onomatopoeia is at play in that usage. 
quences, puts the worst interpretation on the ease of divine action described by $x$ oú $\varphi \omega \varsigma$ (as in Sappho fr. 16.14; compare Pindar, Pythian 9.11).

In the next line i $\left.i \mu \varepsilon^{\prime}\right] \rho \omega\langle\iota\rangle \lambda v^{\prime}\{!\} \subset \alpha \nu \tau !$ could be a dative of means with $\delta \alpha i ̈ \sigma \delta \eta \nu$, finally supplying a word to specify the problem; the following rov-could provide the familiar, idiomatic 'loosening the knees', although the sentence would become drawn out. I suggest starting a new clause with yov-, so that the persona now, in an abrupt response to her own distress, switches from exclamation

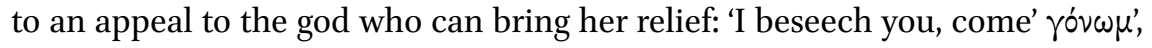
है $\pi \varepsilon[\lambda \theta \varepsilon$. The song would be substantively but not formally cletic. This would give the same train of thought as in Sappho fr. 1, the prayer to Aphrodite, but maintain this song's very different voice. West offers a version that begins a new sentence at the start of line 6 with a negative command structure: $\left.\mu \eta \dot{\eta} \mu^{\prime \prime} \varepsilon\right] \rho \omega\langle\iota\rangle \ldots$ ह้v $\alpha$ [ $p$ p and prolongs the complaint, as in the opening stanza of fr. $1 .{ }^{70}$ Without any evidence for the end of the line or for how the song continues, the choice of structures must remain open, but the tone is clear.

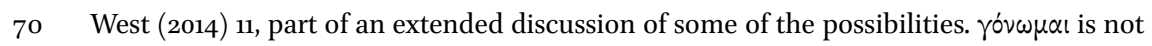
found in Sappho but would be the Aeolic form of a verb found in Homer and Anacreon (so too West). West also reads $\lambda \dot{v} \sigma \sigma \alpha \nu \tau \iota$ as a correction for $\lambda v \iota \iota \alpha \nu \tau l$, still modifying $\varepsilon^{p} \rho \omega\langle\iota\rangle$. While the participle, perhaps 'maddening', 'rabid', is attractive as an easy correction and in sympathy with the sentiment, the aorist is hard to explain and both the parallels he cites for the combination involve very patent personifications, not compatible with a dative of instrument. For a different, very speculative approach I would take a cue from Eur. Med.

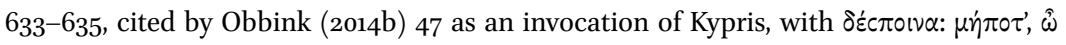

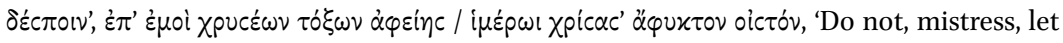
loose upon me from your golden bow an inescapable arrow anointed with desire'. The chorus there seem to wish to avoid the fate suffered in this poem. Although oiø ós should be three-syllables outside Attic, Hamm (1958) 32 §63 indicates the slight possibility of

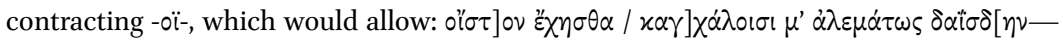
'do you have an arrow ... to pierce me' (but note that the position of the enclitic casts doubt on an epexegetic infinitive). Going further afield, we might consider starting from the assumption that the genitive ending, $i \mu \dot{\varepsilon}] \rho \omega$ is correct, and then looking for an even greater corruption behind the one word that is certainly corrupt, $\lambda v i c \alpha v \tau \iota$. To achieve something parallel to Euripides' $\chi$ pi $\sigma \alpha \sigma \alpha$ we could correct this to whatever might be the Aeolic stem for the Attic $\lambda_{0} \dot{\theta} \theta \varepsilon \tau \alpha$ - an arrow washed in desire (the genitive is normal). For possible verb forms, see LSJ; the word is not documented in Aeolic, and there are several versions of the root, so I would have to assume that the unfamiliarity of the form (perhaps $\lambda \omega \theta$-) led to the original corruption. 


\section{Performance Occasions}

The five love poems, then, differ in tone and in rhetoric. They give very little information about themselves. Only fragment 2, the cletic prayer, has even the pretense of a performance occasion, and given that it suggests the actual presence of a god pouring out nectar for her worshipers, it can only be taken as figurative. In fragment 31 the indistinct "you" to whom the poem is addressed is not necessarily present. The songs must have external audiences, but it would be a methodological mistake to infer the character of the external audience from the rhetoric. Taking each voice in isolation would suggest a different occasion for each, but still lead to no coherent picture of activity. In fr. 16 the persona sounds didactic but that does not mean that Sappho is teaching. The persona in fr. 31 expresses her distance from what she sees, but that does not mean Sappho is alone. If we were to infer the occasions from the poem, they would belong to very different worlds. So in the absence of clues to an occasion, the poems provide no explanation of the differences in voice.

We could attribute the variety in these poems to a typical Greek aesthetic that relishes poikilia and imagine Sappho trying out a number of attitudes, as would be characteristic of the modern notion of lyric, as she explores diverse psychological phenomena and demonstrates them to an undefined audience. It is hard to imagine this as a primarily literary exercise, but perhaps it has a venue in the symposium, and so is a body of work comparable in its variety to that of Archilochus, Hipponax or Anacreon. Certainly it appears to have been received that way in later Athens. But in the end it is hard to conceive of an occasion for a women's symposium, or a collection of women as an audience, unconnected with any other ritual, and it is hard to square an independent body of sympotic love poems with the public responsibilities to family and the celebration of marriage seen elsewhere in the sapphic stanzas of Book One and with the at-least-partially public concern with the Muses seen in the stichic choriambic meters of Books Three and Four. ${ }^{71}$

Perhaps all the poems are just the collected works of a poet for hire, ready to meet any demand, high or low. I suspect that would be anachronistic. However,

71 Stehle (1997) 288-294, 311-318 argued that only written, literary expression provides an explanation. Schlesier $(2013 ; 2014 a)$ has argued for a purely sympotic venue, with Sappho as a participant. Bowie (this volume) suggests that Sappho performed as a professional entertainer in mixed symposia; that does not explain well the exclusion of all but egocentric homoerotic love poems. Parker (1993) 341-346 concludes that Sappho's poems were written for the same variety of cultic, ritual, or social occasions as those of male poets. On dramatic voices in Archilochus and Hipponax, see again West (1974) 1-39. On the role of Anacreon and the Athenian reception, see Nagy (2009c). 
it alerts us to the possibility of songs designed to fit within an occasion. Pindaric epinician offers a kind of parallel: we speak of epinicians as a genre, but just like the erotic poems, they are not a genre in the sense of strictly following a regularized form, as prayers do. There are a number of topics that they must cover and to do so the poet deploys a large number of rhetorical devices and commonplaces. Some are proper especially to the epinician occasion, others are drawn from various sources. He adopts a number of poetic stances and points of view (though without variation as extreme as we see here). And Pindar describes the songs as compliments or adornments to a festival (e.g., Nem. 4.1-5). I suggest that this is the best way to think of the many voices of the erotic poems, that they provide an individual character to the repetitions of a performance in which the assertion of the power of a divinity is required. Since the divinity expresses her power in these poems in a way particular to one social group - women, whether as girls, wives, or potential wives-they could well be the audience, but if the performances are part of a more extensive dramatization, they could also be part of what is represented.

\section{Voices}

But who are the individuals represented by the singing ego? How distinct are they? Are they different poses or different people? To pursue this we can look at the different ways Sappho distinguishes voices; it brings us back to the poem about Charaxos.

\section{Metrical Style}

All the poems we are discussing are, of course, in the Sapphic stanza, but Sappho adapts it to create significant differences. I am looking particularly at her handling of words within the verse line. The patterns for this are mostly the same for Alcaeus and Sappho, but Sappho makes use of variation, and her structures are less rigid and repetitive. Both authors avoid word-end after the fourth syllable but Alcaeus does so more strictly than Sappho. Both prefer word-end after the fifth position-Alcaeus is particularly regular in the second line of the stanza-but Sappho uses the fifth or sixth as alternatives. Because her composition is normally varying, she can mark a poem or passage as a whole by avoiding variation, so that she violates or exaggerates the patterns. For example, in the pathography of fr. 31 she places word-end after the fourth syllable of the lines in unbroken succession until the last surviving line. Conversely, to set out Aphrodite's speech in fr. 1, she starts direct speech after the fifth syllable of the stanza's second line-Alcaeus' most typical break point—and then, restrain- 
ing her normal style of variation, she instead maintains word end in that same position for the whole of Aphrodite's speech. ${ }^{72}$ Metrical style can differentiate voices.

In the Charaxos poem the adonean stands out. Alcaeus' favorite form of the clausula is to put word end after the third syllable; he does this in half of the

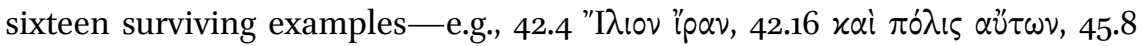

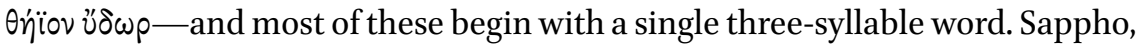
on the other hand, has only three initial trisyllabic words, all in Sappho 1 and none in Aphrodite's speech there. She is also fond of using a single word or

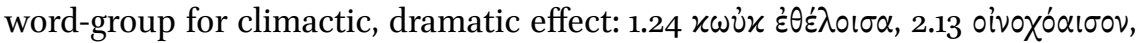
$22.12 \dot{\alpha} \mu \varphi i \pi \dot{\tau} \tau \alpha \tau \alpha$. Her favorite type is an adonean with an initial two-syllable word. But above all, what she does not do is repeat the same structure in stanza after stanza. Yet in this song the first three stanzas all end with the $2+3$

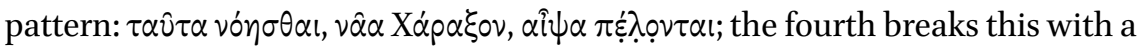
climactic pentasyllabic word-group, xai $\pi 0 \lambda \dot{v} 0 \lambda \beta 01$, leaving Charaxos to turn to Larichos. In context the emphasis is particularly heightened, for the poem ends by reverting to the $2+3$ pattern, $\alpha i \psi \alpha \lambda \dot{\theta} \theta \varepsilon \varepsilon \mu \varepsilon v$. There is no series of clausulas so monotonous in the rest of Book 1.

\section{Linguistic Style}

These adoneans are the most objective but hardly the only characterizing feature of the poem. It has peculiar uses of language. The verb $\theta p \nu \lambda \varepsilon \dot{\varepsilon} \omega$ in line 1 takes some kind of accusative object plus infinitive construction-but $\theta p u \lambda \varepsilon^{\prime} \omega$ is not normally construed with a dependent verb. Once it is found with ö $\tau$ in Plato (Phd. 65b), but it usually takes a neuter direct object. ${ }^{73}$ The construction here does not belong to the poetic language. In the first stanza we also find a $\chi p \eta$ construction; this is the only use of $\chi p \eta$ in the surviving corpus of Sappho, although Alcaeus uses it several times. Perhaps that is a clue

72 I am summarizing my own counts, not including the new texts, without details. The degree of variation depends on whether the count includes only appositive groups or all separate words (both methods have a scholarly history). Since the third hendecasyllabic sequence does not show more differences from either of the previous two than they do from each other, I am ignoring any theories of colometry in this count. No word-ends dependent on conjecture or emendation were included.

73 This conclusion is based on a search of the stems $\theta \rho \nu \lambda$-, $\varepsilon \theta \rho \nu \lambda$ - and $\tau \varepsilon \theta \rho \nu \lambda$; the citation of the Plato example in LSJ leaves the misimpression that it is typical. There is also an instance with $\omega \varsigma$ in Arist. Ath. Pol. 16.7.4 (if correctly supplemented), and once, in Strabo Geog. 8.6.12.3-4, the perfect passive is used impersonally (like $\lambda \varepsilon \dot{\varepsilon} \varepsilon \tau \alpha \mathrm{l}$ ), with हival as a subject infinitive. 
to the kind of tone we find here. In all the rest of Sappho, I count at most ten subjunctives. The only future looking subjunctives are one or two with w's; another appears to be deliberative in an indirect question, and the majority are in present general constructions. ${ }^{74}$ But the Charaxos poem alone has four

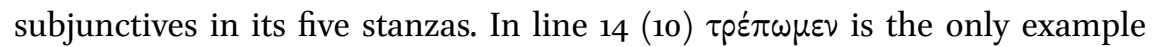
of a hortatory subjunctive in Sappho (Alcaeus has several). In the last stanza, the two subjunctives belong to the only future anticipatory (future more vivid) condition in Sappho.

This collection of unusual constructions has a context, for it has been widely noted that the grammar of the song in some places is, to put it bluntly, strange. The unique $\chi p \eta$ introduces a compound construction with three infinitives, the last of which has a dependent object infinitive that in turn has two dependent object infinitives. In the fourth stanza the conditional relative clause with $\tau \hat{\omega} \nu$ has produced much comment. I think that it is not as far-fetched as some have taken it to be, and certainly does not call for us to substitute a lectio facilior in our copies. The initial genitive is subjective with $\pi$ óvav and also represents the omitted accusative object of $\pi \varepsilon \rho \tau p o ́ \pi \eta \nu$. In English we can say 'those whom Zeus wishes a helper daimon to turn from their troubles,' but it is not idiomatic to say 'those from whose troubles Zeus wishes a helper daimon to turn them,' even though the meaning would be identical. ${ }^{75}$ But it is still a complex construction, not made easier by the postponed antecedent. It would fit more comfortably in prose.

74 Present general: 5.3, 16.3-4, 16a.30-31 (previously 26.3), 60.6, 98.3, and now, apparently, 16.14; purpose with $\omega \varsigma 6.8$, purpose or result with $\langle\dot{\omega} \varsigma\rangle$ 30.7-9 (both with $1 \delta \omega \mu \varepsilon v$ ); indirect deliberative 51; possible anticipatory in 88.16 but Voigt suspects the form. I do not include 31.7, where the reading $\omega \varsigma$ s... $i \delta \omega$ as another present general construction depends on how the line is supplemented and is unlikely (Lidov [1993]). In Alcaeus, I count 15 subjunctives, most of which do refer to time subsequent to that of the leading verb.

75 My understanding of the construction begins with a straightforward expression of the

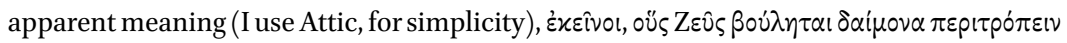
$\dot{\varepsilon} \chi \tau \hat{\omega} \nu \pi \dot{o} v \omega \nu$. A subjective or possessive genitive, referring back to $\dot{\varepsilon} \varkappa \varepsilon \hat{\imath} \nu 01$, is implied with

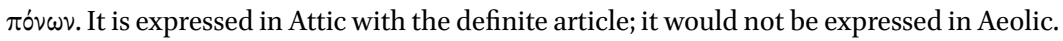
The relative pronoun, whose antecedent is likewise $\dot{\varepsilon} x \varepsilon \hat{\imath} \nu \mathrm{ol}$, and which is in the accusative case as object of $\pi \varepsilon \rho \imath \tau \cos ^{\prime} \tau \varepsilon v$, is then assimilated to that genitive. At that point it may seem that the relative expresses the subjective or possessive genitive with $\pi \dot{o v \omega v}$ and that the accusative object of $\pi \varepsilon \rho \imath \tau \rho \cos \pi$ is implied, not expressed. Since they are the same people, it makes no difference. Obbink (2014b) 44 notes the use of the relative with $x \varepsilon$ in the sense of the indefinite; this usage is confirmed in Alc. fr. $35^{8.6-7 .}$ 


\section{The Voices of the Charaxos Song}

The singer of these awkward lines is the person I identified at the beginning as the subject of $\pi \dot{\varepsilon} \mu \pi \eta v$. The ritual involved at this point has a clear literary parallel, in Il 6.269-278, 293-310, where Hector sends Hecuba to order the priestess Theaino to pray to Athena, and such processions are well-represented

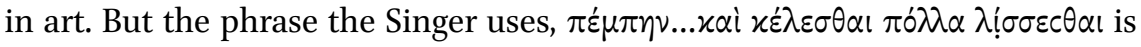
curious (however है $\mu \varepsilon$ is construed). It is not an established poetic expression with this meaning. I have found no example for the conjunction of $\pi \dot{\varepsilon} \mu \pi \varepsilon i v$ and

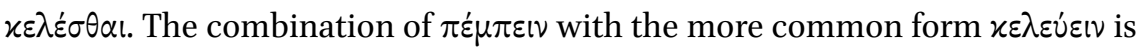
found four times in the Odyssey, in a different sense. There, it always means 'urge to send (Odysseus) on his/my way' (e.g, 7.226). It is found once in Pindar in the sense close to ours, using the participle: 'sending the attendants, she ordered them to ...' (Ol. 6. 32-33). But it does become much more frequent in later Greek prose, for sending one person (not always specified) to urge another to do something, or sending someone someplace with orders to do something. Thucydides typically uses it with the participle. The two verbs joined by $x \alpha$, as in line 9, are found in Xenophon, both with and without the person sent being specified. ${ }^{76}$

We would not normally look to later prose to explain an early poetic idiom, but here, as with $\theta \rho \nu \lambda \varepsilon \varepsilon^{\omega} \omega$, it is precisely the fact that the expression might not be poetic that is the significant point. It also helps clarify that for this speaker the object of $\pi \varepsilon \dot{\varepsilon} \mu \varepsilon \varepsilon \nu$ need not be important. We can supply, as presupposed, the 'you' of the previous sentence; if the song is performed by or in front of the chorus, the performance context would automatically supply an object. But it is not significant within the sentence. Similarly it is not clear who is to beseech Hera. A priestess can be implied. If the Messon precinct is to be assumed, its rituals can also be assumed. Or perhaps the person sent should also pray. But the speaker is not making a point of her own or any one else's participation in the ritual; as I note above, the emphasis is on the ritual. The speaker herself is the one who sends. She is a person of authority; someone who chides those around her and tells them what to do; who uses expressions of necessity or of will not found elsewhere; who, certainly, with her prose-like constructions, bordering on awkwardness, and with her repetitive cadences, does not sound like someone with the habit or even ability to compose songs for a chorus. Perhaps she sounds like somebody's mother (assuming the speaker is

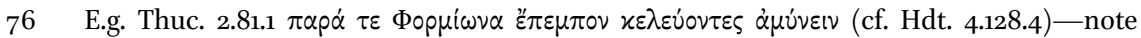
that in this case the object of $\pi \varepsilon \dot{\varepsilon} \mu \pi \varepsilon v$ is not specified. Xen. Anab. 5.6.21, $\pi \dot{\varepsilon} \mu \pi 0 v \sigma l \pi$ pòs

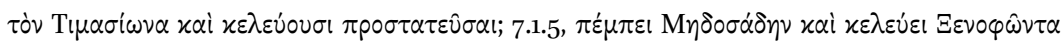
$\sigma \nu \mu \pi \rho \circ \theta \nu \mu \varepsilon i \sigma \theta \alpha$ l. 
a woman; the poem gives no clue), but that is dangerous to say in a poem that gives names but no family markers (unlike the Nereid poem which has family roles but not names). The addressee of the poem, on the other hand, might well have a singer's abilities, especially if she is the one to go perform the prayer.

When the poem was first published, the awkwardness of its language was widely commented on, as if at last we had proof of Page's disparagement, 'additions to the text of Sappho have shown that much of her poetry was below the standard by which we were accustomed to judge her. ${ }^{77}$ That the impression of a non-poetic quality is correct is confirmed by close inspection. What is not correct is that it reflects the author's limitations rather than her intentions. For all the oddities, this poem, or song, as a whole is not awkward. The play with metrical style is restricted to the adoneans; the rest is as varied and expressive as ever. The lines echo each other with the strategically placed repetitions of $\tau \rho \varepsilon \dot{\varepsilon} \pi \omega$ compounds (14 [10] and 19 [15]), of $\dot{\varepsilon} x+$ a burden (15 [11], 18 [14], and 23 [19]), of $\alpha i \psi \alpha(16$ [12] and 24 [20]) and of forms of $\alpha \mu \mu \varepsilon$ beginning stanzas (13 [9] and 21 [17]). ${ }^{78}$ It displays a careful construction. First the speaker bluntly negates simple and vain expressions of hope, then rebuilds the wishes in a series of crescendos: a respectful prayer for safety, a reminder of their dependence on the gods - in metaphor whose vehicle, stormy weather, is neatly matched to its tenor, the threat of storms at sea-and a recognition that this very dependence leaves room for Zeus to do even more by sending his agent to bring about all conceivable success. All this is capped by the hope that Larichos' achievement in the marital and civic sphere can release all their anxieties. ${ }^{79}$ It is the persona of the singer, not the poem itself, that sounds awkward. The composition itself has the adroitness of structure and imagery of a work true to our highest standards for Sappho, for it is a tour-de-force of personification, or prosopopoeia.

77 Page (1959) 110. See also Liberman (2014) 7 , 'This rather prosaic poem .... This was also my own first reaction.

78 For the first, see the report of Jim Powell's remarks in Obbink (2015a) 4; the second I owe to discussions at a symposium held at Bard College in the Fall of 2014; the third and fourth have been widely observed.

79 The series is framed by the conventional Greek triad of natural goods, material goods, and

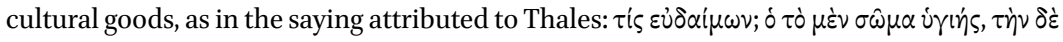

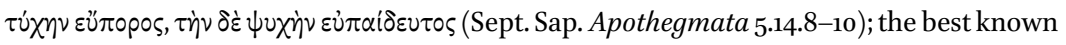
example, of course, is Pindar's 'water, gold, games.' (See too Race 1981 on the opposition of what men need for life and for achievement. It is important to note that the triad may, but need not, be a hierarchy). Here it appears as $\sigma \dot{\alpha} \alpha \nu . . . \pi 0 \lambda \dot{0} 0 \lambda \beta 01 . . . \kappa \varepsilon \varphi \alpha^{\prime} \lambda \alpha \nu \alpha \dot{\varepsilon} \rho p \eta$. If the middle term implies a spiritual blessedness, it may correspond better to the variant $\tau \dot{\eta} \nu \delta \dot{\varepsilon}$

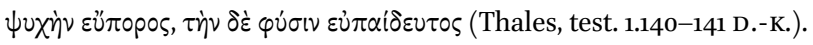


Because we lack the initial one or two stanzas, we cannot say whether this is the persona of the whole poem, or only of one speaker within it. The poem need not dramatize only one character, as $\alpha \ddot{\alpha} i \theta^{0} \hat{\lambda} \eta \sigma \theta \alpha$ makes clear. The addressee, whoever he or she is, is given to vain wishes or (if $\dot{\varepsilon} \lambda \theta \eta \nu$ is a historical aorist) false inferences. ${ }^{80}$ The repeated speech may be something outside the poem, and be part of a characterization of the addressee that began earlier, but it may refer to the content of an earlier stanza spoken by the addressee. I offer, only as an illustration of this idea, a pastiche of Sapphic phrases beginning with a pi that could be taken up by the second speaker at the start of the surviving stanza:

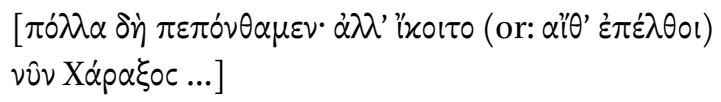

Much have we suffered; may Charaxos now come!

In that case there would be a change in the personae cantantes within the poem. I emphasized earlier that the opening of the song makes clear the nature and urgency of the immediate problem, but there is no need to assume that this is presented simply as an objective fact. Although we do not have what we need to reconstruct an initial stanza that would establish the full context for us, and make precise who the speakers in this drama are, it is a further marker of the poet's skill that the use of characterization appears clearly.

\section{Summary and Hypotheses}

Until now, the remains of prayers for safe return have been so incomplete that they made stylistic comparison or commentary difficult. We can now see that they do proceed through a common structure, both in general form and topics, but that does not contradict the fact that we can also see that they are very different from each other. The Charaxos poem may represent an extreme case

8o I agree with Lardinois, this volume, that $\varepsilon^{2} \lambda \theta \eta \nu$ is most likely future-looking, in effect representing an original idea expressed with an optative of wish or a third-person imperative; however, it could be a historic infinitive in indirect discourse, if the addressee had said "he left (here) with a full ship" (a suggestion of Mark Griffith reported in Obbink [2015b] 3) or "he arrived (there) with a full ship" (suggested to me in email by W. Tortorelli), in either case supposing that these were grounds for believing that he would return successfully. 
but I doubt it is unique. It sounds very different from the Nereid poem, and neither adopts the formal elements of the prayer to Hera. Perhaps we can take the more evident characterization in this new song as a pointer to what is happening throughout, that individual poems represent individual speakers. Their variety of tones or voices need not be representations of the poet herself. They are enactments that dramatize anxieties and hopes, both personal and communal. The dramatization could be pure representation or, in context, have some degree of narration. Our awareness that the voices are constructed invites us as literary analysts to find a current of thought in tension with the overt one, and this is no less true of the Charaxos poem than it is of the Prayer to Aphrodite, fr. 1, or the Priamel poem, fr. 16. Nonetheless the overt voice requires an occasion, and this invites us to look for a way to place the poems in a cultural context.

The internal evidence leaves many questions unanswered, but gives us parameters within which to discuss them. Also, we cannot know how many types of ceremony are involved. It is notable that the conception of Aphrodite, which binds almost all the poems, is quite consistent. She is active in promoting love, and her presence is desirable but can be intrinsically painful (like Eros

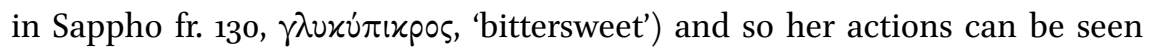
as hostile, with a military metaphor. The military images $\sigma \dot{u} \mu \mu \alpha \chi \circ \varsigma$ at the end of fr. 1 and possibly $\delta \alpha i \sigma \delta[$ in line 5 of the Kypris song, and the simultaneous rejection of military beauty and the fusion of it into the beloved in fr. 16 would be consistent with the possible pugilistic image at the end of the Charaxos poem. Possible supplements portraying Kypris on the offensive at the end of fragments 5 and 15 might invoke her presence as the god who arouses desire. There is also a strong presence of Dionysus; more or less overtly in some of the prayers for safety, but as a Dionysiac element in the wine-image of fr. 2 and generally in the 'madness' of love, which is elsewhere a topic of the symposium. ${ }^{81}$ But that does not mean that the poems of both types do or do not belong to one type of event.

At one extreme, the love poems may mark a separation from some sort of group for whose members it was age- or status-appropriate to define themselves in terms of Aphrodite (as in fr. 2), whatever the group's actual functionperhaps to practice performing in choruses or to participate in initiatory ceremonies - and they may or may not have connection to marriage (or only incidentally), while the prayers for return may represent homecoming ceremonies

81 Both the dramatic character and the Dionysiac element of Sappho's erotic poems are discussed in Nagy (2007b). 
enacted on various different occasions, as the local aristocrats exercised (or were excluded from) their political power and social roles, including opportunities for travel and marriage. ${ }^{82}$

At the other extreme, the love poems (fr. 2 apart) center on loss, and it is easy to suppose that the loss was occasioned by the marriage of a member of the group. This seems especially likely in the case of fr. $16 .^{83}$ The prayers for safe return appear to end by looking forward to marriage, so one could imagine-if I am correct that they are dramatic reenactments-a connection between the ceremonies celebrating homecoming and ceremonies of marriage in a multipart festival at Hera's temenos. The common stanza form would reflect this unity. In dramatic reenactments focusing variously on different parts of a series of events it would not be necessary that the performing persona be a woman in the poems directly reenacting prayer for the arrival of a male traveller. Neither fr. 5 nor the Charaxos poem give an indication of gender, and, depending on the supplements, fr. 17 also might not. In addition, the connection to Dionysus may be an early indication of his importance in dramatic performances.

The internal evidence does suggest what Sappho did as a poet. Whether the occasion called for the topic of mortal dependence on the divine powers governing passion, or for a prayer requesting safe return and the favor of the goddess of marriage, Sappho provided songs for the reiterations of formal ceremonies that enacted common concerns. We cannot say whether she herself took on new roles in successive performances or provided roles for other women or men who were members of her community. The repetition implies that in many of the cases we see stock characters and situations. But no two versions, or no two prompting occasions, or maybe not any two performers, would be identical. Part of Sappho's art (perhaps the part we value most) was her ability to give to particular experiences a form of expression in which we,

82 We may take it for granted that in reality marriage among the Lesbian elite was based on political and economic considerations, but the poetry follows a convention in which marriage fulfills desire. Outside Book I, that appears plainly in Sappho fr. 112, and explains why the expression of erotic themes is consistent in the love poems and the travellers' poems. Note that if aristocratic activity included bringing home brides to marry as part of the strengthening of ties outside the island (rather than coming home to them, as in the next model I propose), fr. 44, the return of Hector with Andromache, would fit into the context. Caciagli in this volume rightly warns that the Messon temenos would have been the site for a number of different ceremonies.

83 See Lardinois (2001) 80-91 on the close relation of songs of loss and lament to songs for or about brides. 
like her audiences, can locate our own, and so have a basis for appreciating the experience of other persons, times, and places. And part of how she did so was to give the different versions different voices. 